\title{
Simulation study for ground-based Ku-band microwave observations of ozone and hydroxyl in the polar middle atmosphere
}

\author{
David A. Newnham ${ }^{1}$, Mark A. Clilverd ${ }^{1}$, Michael Kosch ${ }^{2,3}$, Annika Seppälä ${ }^{4}$, and Pekka T. Verronen ${ }^{5}$ \\ ${ }^{1}$ British Antarctic Survey (BAS), High Cross, Madingley Road, Cambridge, CB3 0ET, UK \\ ${ }^{2}$ Physics Department, Lancaster University, Lancaster, LA1 4YB, UK \\ ${ }^{3}$ South African National Space Agency (SANSA), Hospital Street, Hermanus 7200, South Africa \\ ${ }^{4}$ Department of Physics, University of Otago, P.O. Box 56, Dunedin 9054, New Zealand \\ ${ }^{5}$ Space and Earth Observation Centre, Finnish Meteorological Institute, Helsinki, Finland
}

Correspondence: David A. Newnham (dawn@bas.ac.uk)

Received: 26 September 2018 - Discussion started: 16 November 2018

Revised: 8 February 2019 - Accepted: 11 February 2019 - Published: 1 March 2019

\begin{abstract}
The Ku-band microwave frequencies (10.7014.25 GHz) overlap emissions from ozone $\left(\mathrm{O}_{3}\right)$ at $11.072 \mathrm{GHz}$ and hydroxyl radical $(\mathrm{OH})$ at $13.441 \mathrm{GHz}$. These important chemical species in the polar middle atmosphere respond strongly to high-latitude geomagnetic activity associated with space weather. Atmospheric model calculations predict that energetic electron precipitation (EEP) driven by magnetospheric substorms produces large changes in polar mesospheric $\mathrm{O}_{3}$ and $\mathrm{OH}$. The EEP typically peaks at geomagnetic latitudes of $\sim 65^{\circ}$ and evolves rapidly with time longitudinally and over the geomagnetic latitude range $60-80^{\circ}$. Previous atmospheric modelling studies have shown that during substorms $\mathrm{OH}$ abundance can increase by more than an order of magnitude at $64-84 \mathrm{~km}$ and mesospheric $\mathrm{O}_{3}$ losses can exceed $50 \%$. In this work, an atmospheric simulation and retrieval study has been performed to determine the requirements for passive microwave radiometers capable of measuring diurnal variations in $\mathrm{O}_{3}$ and $\mathrm{OH}$ profiles from high-latitude Northern Hemisphere and Antarctic locations to verify model predictions. We show that, for a $11.072 \mathrm{GHz}$ radiometer making $6 \mathrm{~h}$ spectral measurements with $10 \mathrm{kHz}$ frequency resolution and rootmean-square baseline noise of $1 \mathrm{mK}, \mathrm{O}_{3}$ could be profiled over $8 \times 10^{-4}-0.22 \mathrm{hPa}(\sim 98-58 \mathrm{~km})$ with $10-17 \mathrm{~km}$ height resolution and $\sim 1 \mathrm{ppmv}$ uncertainty. For the equivalent $13.441 \mathrm{GHz}$ measurements with vertical sensor polarisation, $\mathrm{OH}$ could be profiled over $3 \times 10^{-3}-0.29 \mathrm{hPa}(\sim 90-56 \mathrm{~km})$ with $10-17 \mathrm{~km}$ height resolution and $\sim 3$ ppbv uncertainty. The proposed observations would be highly applicable
\end{abstract}

to studies of EEP, atmospheric dynamics, planetary-scale circulation, chemical transport, and the representation of these processes in polar and global climate models. Such observations would provide a relatively low-cost alternative to increasingly sparse satellite measurements of the polar middle atmosphere, extending long-term data records and also providing "ground truth" calibration data.

\section{Introduction}

\subsection{Background information}

Energetic particle precipitation (EPP) is an important mechanism in the polar middle and upper atmosphere, causing ionisation in the neutral atmosphere and producing odd nitrogen $\left(\mathrm{NO}_{x}=\mathrm{NO}+\mathrm{NO}_{2}\right)$ and odd hydrogen $\left(\mathrm{HO}_{x}=\mathrm{OH}+\right.$ $\mathrm{HO}_{2}$ ) (Brasseur and Solomon, 2005; Mironova et al., 2015; Sinnhuber et al., 2012; Verronen and Lehmann, 2013). Enhanced abundances of these chemical species lead to catalytic destruction of ozone $\left(\mathrm{O}_{3}\right)$ (Jackman and McPeters, 2004), perturbing the radiative balance, dynamics, and largescale circulation patterns of the atmosphere. This mechanism potentially links solar variability associated with space weather to regional surface climate (e.g. Arsenovic et al., 2016; Baumgartner et al., 2011; Semeniuk et al., 2011; Seppälä et al., 2009, 2013). The energetic particles, mainly protons and electrons of solar and magnetospheric origin, vary widely in energy range and the regions of the atmosphere 
where they impact, in both geographic-geomagnetic coverage and altitude. Energetic electron precipitation (EEP), with electron energies in the range $20-300 \mathrm{keV}$, increases ionization in the polar mesosphere at altitudes of 60-90 km (Newnham et al., 2018a; Turunen et al., 2009).

Atmospheric model calculations (Seppälä et al., 2015) predict that EEP driven by magnetospheric substorms produces large changes in polar mesospheric $\mathrm{O}_{3}$ and $\mathrm{HO}_{x}$. The EEP typically peaks at geomagnetic latitudes of $\sim 65^{\circ}$ (e.g. Kilpisjärvi, Finland, and Syowa station, Antarctica) and evolves rapidly with time eastwards and over the geomagnetic latitude range $60-80^{\circ}$ (Cresswell-Moorcock et al., 2013). During the substorms the modelled night-time $\mathrm{OH}$ partial column over the altitude range $64-84 \mathrm{~km}$ can increase by more than $1000 \%$ and the $\mathrm{OH}$ volume mixing ratio (VMR) at $70 \mathrm{~km}$ increases from the background (i.e. no substorm) level of $\sim 8$ to $\sim 60 \mathrm{ppbv}$ (Seppälä et al., 2015). The substorms leave footprints of 5\%-55\% mesospheric $\mathrm{O}_{3}$ loss lasting many hours of local time, with strong altitude and seasonal dependences (Seppälä et al., 2015). The cumulative atmospheric response of $\sim 1250$ substorms yr $^{-1}$ (Rodger et al., 2016) is potentially more important than the impulsive but highly sporadic (about three to four per year) effects of solar proton events. Other recent studies suggest that EEP from the Earth's outer radiation belt continuously affects the composition of the polar mesosphere through $\mathrm{HO}_{x}$-driven chemistry (Andersson et al., 2014a) and that $\mathrm{HO}_{x}$ may cause prolonged mesospheric $\mathrm{O}_{3}$ depletion when $\mathrm{NO}_{x}$ is enhanced during polar winter (Verronen and Lehmann, 2015). Mesospheric $\mathrm{OH}$ is predominantly produced by the photodissociation of water vapour $\left(\mathrm{H}_{2} \mathrm{O}\right)$ and $\mathrm{HO}_{x}$ measurements can also be used as a proxy for mesospheric $\mathrm{H}_{2} \mathrm{O}$ (Summers et al., 1997). In order to test, verify, and improve models of the polar stratosphere and mesosphere, $\mathrm{O}_{3}$ and $\mathrm{OH}$ observations are needed with sufficient precision and time resolution to characterise the different processes that modify their chemical abundances. This paper identifies the instrument characteristics that would be needed to produce the required observations.

\subsection{Previous mesospheric ozone and hydroxyl measurements}

$\mathrm{O}_{3}$ vertical profiles retrieved in the upper mesosphere (70$100 \mathrm{~km}$ ) from observations by nine recently operating satellite instruments have been reviewed and compared (Smith et al., 2013). The comparison of coincident profiles showed that upper mesospheric ozone is abundant during the night and depleted during the day, the secondary $\mathrm{O}_{3}$ VMR maximum occurs at 90-92 km during the day and $95 \mathrm{~km}$ at night, and $\mathrm{O}_{3} \mathrm{VMR}$ is very low $(<0.2 \mathrm{ppmv})$ at about $80 \mathrm{~km}$ during both day and night with a minimum in ozone density at sunrise at $80 \mathrm{~km}$. The Microwave Limb Sounder (MLS) on the Aura satellite has provided a long time series of stratospheric and mesospheric $\mathrm{O}_{3}$ measurements (Froidevaux et al., 2008) with global coverage, although the precision of retrieved $\mathrm{O}_{3}$ profiles decreases sharply above $0.1 \mathrm{hPa}(\sim 64 \mathrm{~km})$. MLS observations of mesospheric OH (Pickett et al., 2008) have also helped to elucidate the role of different types of EPP in polar $\mathrm{O}_{3}$ variability (e.g. Andersson et al., 2014b; Verronen et al., 2011; Zawedde et al., 2018). Minschwaner et al. (2011) reviewed $\mathrm{OH}$ in the stratosphere and mesosphere and used MLS data to study its diurnal variability. The Spatial Heterodyne Imager for Mesospheric Radicals (SHIMMER) (Englert et al., 2010) measured $\mathrm{OH}$ diurnal variations for investigations into discrepancies in mesospheric $\mathrm{HO}_{x}$ in photochemical models that had been suggested by earlier satellite observations (Siskind et al., 2013). A major limitation of satellite observations is that the temporal and spatial sampling arising from several overpasses per day at polar locations can make investigating rapidly evolving short-term chemical changes, such as those induced by substorms, a challenge.

Ground-based millimetre-wave radiometry at 110 $250 \mathrm{GHz}$ provides continuous measurements of $\mathrm{O}_{3}$ (e.g. Hartogh et al., 2004; Daae et al., 2014; Ryan et al., 2016) and perhydroxyl radical $\left(\mathrm{HO}_{2}\right)$ (Clancy et al., 1994) but the altitude range is typically restricted to $\sim 20-75 \mathrm{~km}$. Above $\sim 75 \mathrm{~km}$, thermal Doppler broadening increases and lower-pressure/higher-altitude information cannot be retrieved from the emission lines. However, for the $\mathrm{O}_{3}$ microwave line centred at $11.072 \mathrm{GHz}$ the atmosphere is much less opaque and Doppler broadening is 10-23 times lower than at $110-250 \mathrm{GHz}$, allowing the retrieval of $\mathrm{O}_{3}$ VMR to higher altitudes. Low-cost ground-based microwave radiometers operating at $11.072 \mathrm{GHz}$ have been developed using inexpensive $\mathrm{Ku}$-band satellite television low-noise block (LNB) downconverters (Rogers et al., 2009, 2012). Applying a straightforward processing scheme, $\mathrm{O}_{3}$ partial columns for the lower mesosphere $(\sim 50-80 \mathrm{~km})$ and the upper mesosphere-lower thermosphere $(\sim 80-100 \mathrm{~km})$ have been determined from the central $1.25 \mathrm{MHz}$ section of observed $11.072 \mathrm{GHz} \mathrm{O}_{3}$ spectra. The current observations can broadly estimate seasonal $\mathrm{O}_{3}$ variability near the mesopause but would not readily resolve the altitude-dependent $\mathrm{O}_{3}$ changes at $60-90 \mathrm{~km}$ that are predicted to occur with substorms. Furthermore, due to the weakness of the $11.072 \mathrm{GHz}$ emission line, measurement times extend to days using a single receiver radiometer achieving a root-mean-square $(\mathrm{rms})$ noise level $(1 \sigma)$ of $5 \mathrm{mK}$ at $9.8 \mathrm{kHz}$ resolution and with $24 \mathrm{~h}$ signal integration.

Remote-sensing measurements of mesospheric $\mathrm{OH}$ abundances from the ground are challenging due to the low VMR, which typically peaks in the parts per billion by volume range at $\sim 80 \mathrm{~km}$. Ground-based lidars at mid-latitude sites have detected and identified $\mathrm{OH}$ in the ground vibrational state, $X^{2} \Pi\left(v^{\prime \prime}=0\right)$, in the mesosphere at $\sim 75-85 \mathrm{~km}$ altitude (Brinksma et al., 1998a, b). The lidar measurements detect UV resonant fluorescence at $\sim 308 \mathrm{~nm}$ from the $\mathrm{OH}$ $A^{2} \Sigma-X^{2} \Pi$ electronic transition. In contrast, near-infrared 
and visible airglow emissions in the $X^{2} \Pi$ ro-vibrational Meinel system are due to deactivation of vibrationally excited $\mathrm{OH}^{*}\left(v^{\prime}=7\right.$ to $\left.v^{\prime}=9\right)$ generated by the highly exothermic reaction of atomic hydrogen with $\mathrm{O}_{3}$. Satellite measurements of Meinel band nightglow have shown that $\mathrm{OH}^{*}$ occurs in a $\sim 8 \mathrm{~km}$ thick layer near $90 \mathrm{~km}$ (Zhang and Shepherd, 1999). Ground-based spectroscopic measurements of individual $\mathrm{OH}$ vibrational bands in the Meinel emissions can be used to infer temperatures at the mesopause region and estimate relative populations of the $v^{\prime}$ states (e.g. von Zahn et al., 1987; Yee et al., 1997; Smith et al., 2010).

\subsection{This work}

In this work we investigate the potential for measuring diurnal variations in the vertical profiles of $\mathrm{O}_{3}$ in the mesosphere and lower thermosphere using the $11.072 \mathrm{GHz}$ emission line and extending the ground-based microwave radiometry technique to mesospheric $\mathrm{OH}$ emissions at $\sim 13.4 \mathrm{GHz}$. The microwave spectrum of the most abundant hydroxyl isotopomer, ${ }^{16} \mathrm{OH}$, at $13.433-13.442 \mathrm{GHz}$ shows four closely spaced lines which arise from the $\Lambda$-doubling hyperfine structure in the rotational ${ }^{2} \Pi_{3 / 2}(v=0, J=7 / 2)$ state (Radford, 1961; Sastry and Vanderlinde, 1980). The atmospheric $\mathrm{OH}$ spectrum is further complicated by the magnetic Zeeman effect, due to the molecule's non-zero total electron spin quantum number $(S=1 / 2)$. Each line is Zeeman split into several components polarised in a quasi-symmetric manner and shifted from the central frequency. Here we investigate potential measurements using the most intense of the four $\mathrm{OH}$ rotational lines, which has a line position of $13.441 \mathrm{GHz}$.

The study focuses on atmospheric simulations and retrievals for Kilpisjärvi, Finland, since model data for $\mathrm{O}_{3}$ and $\mathrm{OH}$ abundances in substorm and background (no substorm) conditions are available for this location. However, we demonstrate the technique's wider applicability by comparing atmospheric microwave transmittances at six landbased locations including Kilpisjärvi, shown on the maps in Fig. 1. Three potential sites for ground-based instruments are in the Antarctic and three are at high latitudes in the Northern Hemisphere $(\mathrm{NH})$, and all are located close to geomagnetic latitude $65^{\circ}$ where substorms are predicted to have the greatest effect on mesospheric $\mathrm{O}_{3}$ and $\mathrm{OH}$.

\section{Methodology}

Microwave spectrum simulations and retrievals have been performed using atmospheric model datasets in radiative transfer calculations for selected high-latitude and polar locations. The synthesis of VMR profiles at these locations for $\mathrm{O}_{3}, \mathrm{OH}$, and seven other atmospheric species, as well as temperature profiles, from available model data is described in Sect. 2.1. The configuration of the radiative transfer forward model for simulating clear-sky atmospheric microwave transmittance and brightness temperature spectra is given in Sect. 2.2, and the setups for performing $\mathrm{O}_{3}$ and $\mathrm{OH}$ retrievals for Kilpisjärvi, Finland, are given in Sect. 2.3.

\subsection{Atmospheric model datasets}

Nine chemical species were identified as significant contributors to the clear-sky atmospheric microwave spectrum in the $11-14 \mathrm{GHz}$ region, overlapping the target $\mathrm{O}_{3}$ and $\mathrm{OH}$ lines at 11.072 and $13.441 \mathrm{GHz}$ : ozone $\left(\mathrm{O}_{3}\right)$, hydroxyl radical $(\mathrm{OH})$, water vapour $\left(\mathrm{H}_{2} \mathrm{O}\right)$, molecular nitrogen $\left(\mathrm{N}_{2}\right)$, molecular oxygen $\left(\mathrm{O}_{2}\right)$, perhydroxyl radical $\left(\mathrm{HO}_{2}\right)$, nitric acid $\left(\mathrm{HNO}_{3}\right)$, hydrogen peroxide $\left(\mathrm{H}_{2} \mathrm{O}_{2}\right)$, and carbon dioxide $\left(\mathrm{CO}_{2}\right)$. Monthly mean vertical profiles of VMR for the atmospheric species, and temperature, were calculated using a 10-year dataset from WACCM-D (Verronen et al., 2016) covering 2000-2009. WACCM-D is a 3-D global atmospheric model that incorporates a detailed representation of D-region chemistry in the specified dynamics (SD) version of the Whole Atmosphere Community Climate Model (WACCM 4) (Marsh et al., 2013). The model data were taken from the WACCM-D longitude-latitude grid points closest to the six locations of interest. Seasonal winter mean profiles were calculated using December, January, and February (DJF) data for the NH locations and June, July, and August (JJA) data for the Southern Hemisphere (SH). Similarly, summer mean profiles were calculated using JJA data for the $\mathrm{NH}$ locations and DJF data for the SH locations.

$\mathrm{O}_{3}$ and $\mathrm{OH}$ VMR profiles for substorm and background (no substorm) conditions were computed by combining data from the 1-D Sodankylä Ion-Neutral Chemistry (SIC) model (Verronen et al., 2005) with monthly mean WACCM-D data. The SIC model data provided VMR data over the altitude range $20-100 \mathrm{~km}$, and monthly mean data from WACCM-D filled the region from the ground up to 20 and above $100 \mathrm{~km}$. Figure 2a shows $\mathrm{O}_{3}$ number density profiles calculated using a 9-day SIC model run (Seppälä et al., 2015) for December 2007 with substorm conditions at Kilpisjärvi. The largest decreases in mesospheric $\mathrm{O}_{3}$ abundance, exceeding $50 \%$, occur over the altitude range $68-86 \mathrm{~m}$ during a 4-day period, after which the number densities return to background levels (Fig. 2b). The percentage changes in $\mathrm{O}_{3}$ partial column over altitudes $64-84 \mathrm{~km}$ for the original ( $15 \mathrm{~min}$ ) model resolution and 1,6 , and $24 \mathrm{~h}$ moving-average smoothed data are shown in Fig. 2c. The three smoothed datasets show reduced diurnal variability compared to the original model data but the largest decrease in $\mathrm{O}_{3}$ partial column is little changed by averaging up to $24 \mathrm{~h}$. VMR profiles for substorm and background (no substorm) conditions were determined from the SIC model data coincident with the largest decrease in $\mathrm{O}_{3}$ partial column, and these and the monthly mean profiles are shown in Fig. 2d. Substorm reductions in $\mathrm{O}_{3}$ VMR occur over the altitude range 64-94 km, with the largest decrease at $72 \mathrm{~km}$.

A similar approach was used to determine OH VMR profiles, as shown in Fig. 3. The largest increases in mesospheric 

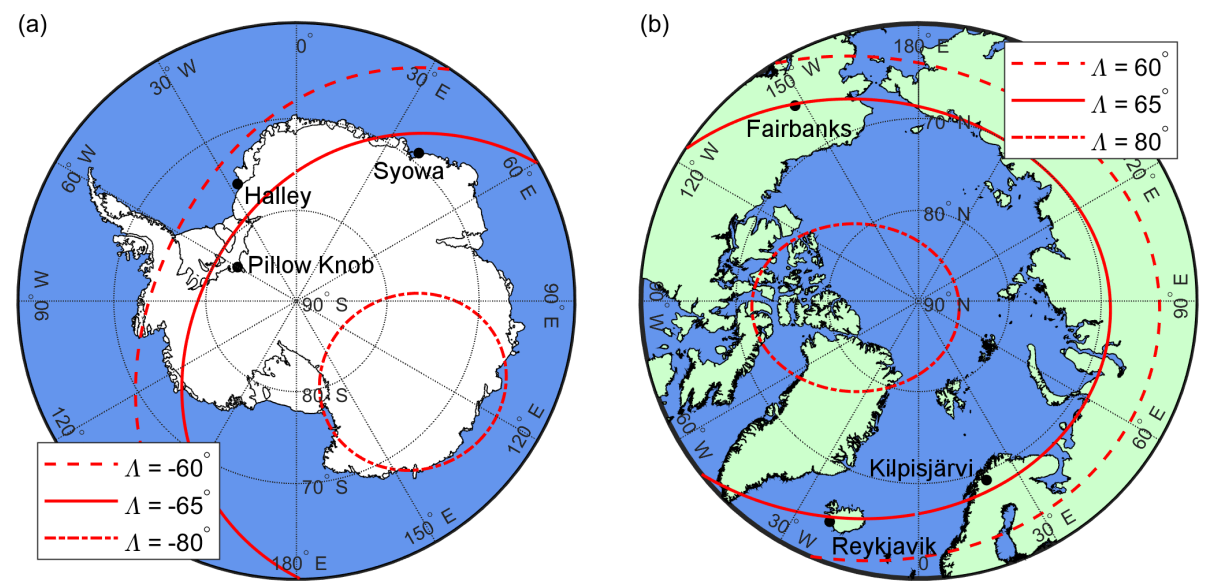

Figure 1. Maps of (a) the Southern Hemisphere and Antarctica poleward of geographic latitude $60^{\circ} \mathrm{S}$ and (b) the Northern Hemisphere and Arctic region poleward of geographic latitude $60^{\circ} \mathrm{N}$. The red dashed, solid, and dotted-dashed lines on each map show the geomagnetic latitudes $\Lambda= \pm 60^{\circ}, \Lambda= \pm 65^{\circ}$, and $\Lambda= \pm 80^{\circ}$ respectively, calculated for 1 January 2015 and an altitude of $80 \mathrm{~km}$ using the IGRF-12 internal field model (Thébault et al., 2015). Black filled circles indicate the locations of Halley station $\left(75^{\circ} 37^{\prime} \mathrm{S}, 26^{\circ} 15^{\prime} \mathrm{W}, \Lambda=-62.3^{\circ}\right.$ ), Syowa station $\left(69^{\circ} 00^{\prime} \mathrm{S}, 39^{\circ} 35^{\prime} \mathrm{E}, \Lambda=-66.6^{\circ}\right)$, and Pillow Knob refuelling station $\left(82^{\circ} 30^{\prime} \mathrm{S}, 60^{\circ} 00^{\prime} \mathrm{W}, \Lambda=-67.3^{\circ}\right)$ in $(\mathbf{a})$ and Kilpisjärvi $\left(69^{\circ} 03^{\prime} \mathrm{N}, 20^{\circ} 49^{\prime} \mathrm{E}, \Lambda=66.2^{\circ}\right)$, Finland; Reykjavik $\left(64^{\circ} 08^{\prime} \mathrm{N}, 21^{\circ} 56^{\prime} \mathrm{W}, \Lambda=64.4^{\circ}\right)$, Iceland; and Fairbanks $\left(64^{\circ} 51^{\prime} \mathrm{N}, 147^{\circ} 43^{\prime} \mathrm{W}, \Lambda=\right.$ $\left.65.2^{\circ}\right)$, Alaska, in (b).
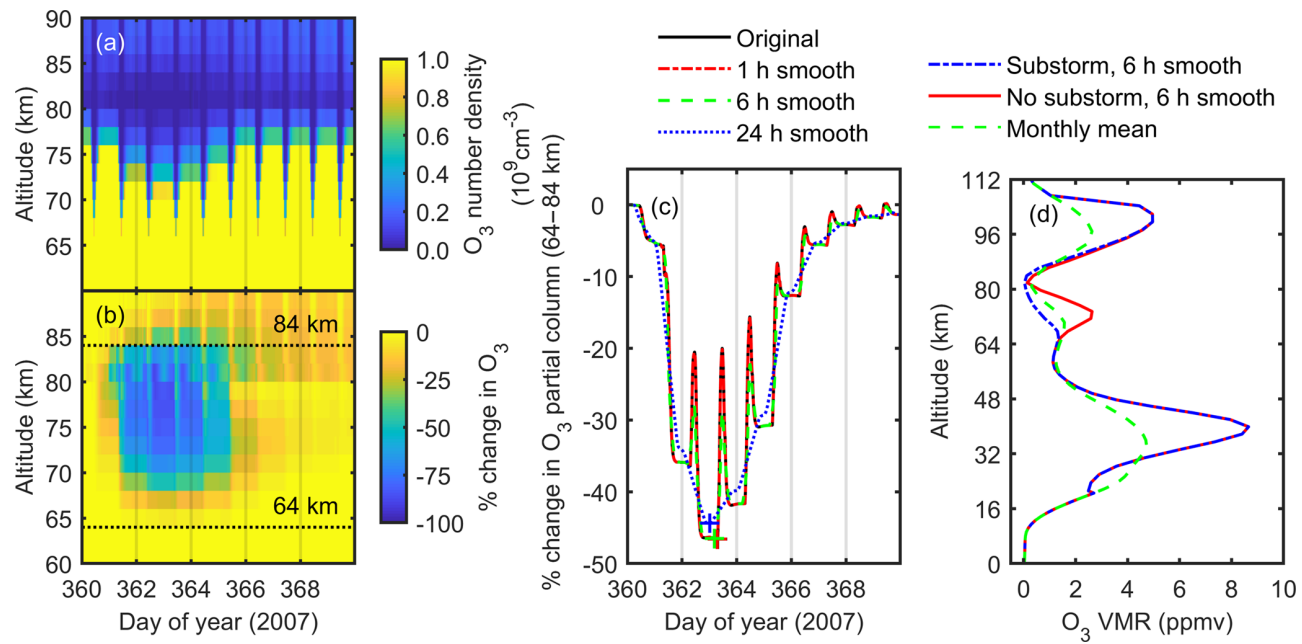

Figure 2. Derivation of ozone $\left(\mathrm{O}_{3}\right)$ volume mixing ratio profiles from atmospheric model datasets. Panel (a) shows $\mathrm{O}_{3}$ number densities calculated by the SIC model for December 2007 substorm conditions at Kilpisjärvi $\left(69^{\circ} 03^{\prime} \mathrm{N}, 20^{\circ} 48^{\prime}\right.$ E), Finland. Panel (b) shows the percentage change in modelled $\mathrm{O}_{3}$ abundance from background (no substorm) conditions. Panel (c) shows the percentage change in $\mathrm{O}_{3}$ partial column over altitudes $64-84 \mathrm{~km}$ during substorm conditions for the original (15 min) model resolution and 1, 6, and $24 \mathrm{~h}$ smoothed data. "+" symbols indicate the largest decreases in $\mathrm{O}_{3}$ partial column at each nominal time resolution. Panel (d) shows the $6 \mathrm{~h}$ smoothed $\mathrm{O}_{3}$ VMR profiles for December substorm, background (no substorm), and monthly mean conditions.

$\mathrm{OH}$ abundance, exceeding 2 orders of magnitude above the background level, occur at altitudes in the range $66-82 \mathrm{~km}$ during the 4 days corresponding to $\mathrm{O}_{3}$ decreases, after which $\mathrm{OH}$ number densities return to background levels (Fig. 3a and $\mathrm{b}$ ). The percentage changes in $\mathrm{OH}$ partial column over altitudes $64-84 \mathrm{~km}$ for the original $(15 \mathrm{~min})$ model resolution and 1, 6, and $24 \mathrm{~h}$ moving averages are shown in Fig. 3c. The enhanced level of mesospheric $\mathrm{OH}$ during substorms shows greater diurnal variability than the corresponding $\mathrm{O}_{3}$ reductions. Smoothing the modelled $\mathrm{OH}$ partial columns significantly reduces the daily maxima, indicating that the improved signal-to-noise ratio from atmospheric measurements longer than $\sim 6 \mathrm{~h}$ would be strongly offset by the smaller integrated $\mathrm{OH}$ signal. The $6 \mathrm{~h}$ smoothed substorm and background (no substorm) VMR profiles corresponding to the largest decrease in $\mathrm{OH}$ partial column, and monthly mean profiles, are shown in Fig. 3d. The substorm profile shows a 

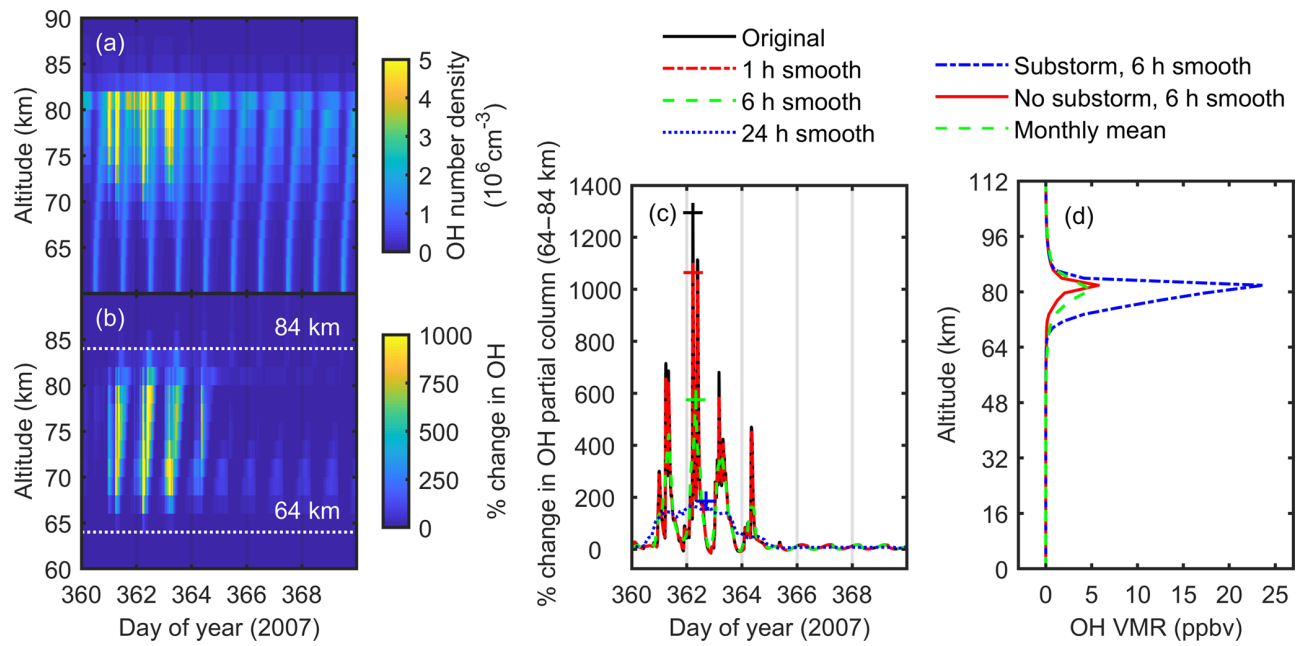

Figure 3. Derivation of hydroxyl radical $(\mathrm{OH})$ volume mixing ratio profiles from atmospheric model datasets. Panel (a) shows $\mathrm{OH}$ number densities calculated by the SIC model for December 2007 substorm conditions at Kilpisjärvi $\left(69^{\circ} 03^{\prime} \mathrm{N}, 20^{\circ} 48^{\prime}\right.$ E), Finland. Panel (b) shows the percentage change in modelled $\mathrm{O}_{3}$ abundance from background (no substorm) conditions. Panel (c) shows the percentage change in $\mathrm{OH}$ partial column over altitudes $64-84 \mathrm{~km}$ during substorm conditions for the original $(15 \mathrm{~min})$ model resolution and 1,6 , and $24 \mathrm{~h}$ smoothed data. "+" symbols indicate the largest increases in $\mathrm{OH}$ partial column at each nominal time resolution. Panel (d) shows the $6 \mathrm{~h}$ smoothed OH VMR profiles for December substorm, background (no substorm), and monthly mean conditions.

5 -fold increase in OH VMR around $82 \mathrm{~km}$ compared to the monthly mean and background (no substorm) data.

\subsection{Forward modelling of atmospheric spectra}

Simulated atmospheric microwave spectra were calculated using version 2.2.58 of the Atmospheric Radiative Transfer Simulator (ARTS) (available at http://www.radiativetransfer. org/, last access: 8 August 2016) (Buehler et al., 2005, 2018; Eriksson et al., 2011) and the Qpack2 (a part of atmlab v2.2.0) software package (Eriksson et al., 2005). ARTS is a monochromatic line-by-line model that can simulate radiances from the infrared to the microwave and has been validated against other models in the sub-millimetre spectral range (Melsheimer et al., 2005). The model includes contributions from spectral lines and broadband continua via a choice of user-specified parameterisations. The Planck formalism was used for calculating brightness temperatures and atmospheric transmittance.

Spectroscopic line parameters for $\mathrm{O}_{3}, \mathrm{OH}, \mathrm{H}_{2} \mathrm{O}, \mathrm{N}_{2}$, $\mathrm{O}_{2}, \mathrm{HO}_{2}, \mathrm{HNO}_{3}, \mathrm{H}_{2} \mathrm{O}_{2}$, and $\mathrm{CO}_{2}$ were taken from the high-resolution transmission (HITRAN) molecular absorption database (Gordon et al., 2017). For all molecules except OH the Kuntz approximation (Kuntz, 1997) to the Voigt line shape with a Van Vleck-Huber prefactor (Van Vleck and Huber, 1977) and a line cut-off of $750 \mathrm{GHz}$ was used, which is valid for the pressures considered. As the water vapour continuum parameterisation, the Mlawer-Tobin Clough-Kneizys-Davies (MT-CKD) model (version 2.5.2) was used, which includes both foreign and self-broadening components (Mlawer et al., 2012). Collision-induced absorp- tion (CIA) is the main contribution to the dry continua in the microwave range, and therefore the CIA parameterisations from the MT-CKD model (Clough et al., 2005) (version 2.5.2 for $\mathrm{N}_{2}$ and $\mathrm{CO}_{2}$ and version 1.0 for $\mathrm{O}_{2}$ ) were applied.

In order to compare seasonal atmospheric transmittances at the six different locations, survey spectra over the frequency range $5-20 \mathrm{GHz}$ were calculated at zenith angles of 0 and $82^{\circ}$ using mean winter and mean summer profiles. A $1 \mathrm{MHz}$ frequency grid was chosen, adequate to characterise smoothly varying broadband transmittance but insufficient to resolve narrowband spectral features.

For simulations of ground-based microwave measurements, values for the frequency resolution, bandwidth, and baseline noise were chosen by considering the range of atmospheric emission line widths and likely instrument performance. Pressure-broadened, Doppler-broadened, and Voigt full-width half-maxima (FWHM) line widths for the lines were calculated using air-broadening coefficients from HITRAN and winter (DJF) and summer (JJA) pressure and temperature profiles at Kilpisjärvi. Figure $4 \mathrm{a}$ and $\mathrm{b}$ show the variation of $\mathrm{O}_{3} 11.072 \mathrm{GHz}$ and $\mathrm{OH} 13.441 \mathrm{GHz}$ line widths with altitude. For both molecules pressure-broadening dominates below $\sim 90 \mathrm{~km}$, increasing rapidly below $85 \mathrm{~km}$ to give FWHM line widths of $300 \mathrm{kHz}$ at $\sim 65-70 \mathrm{~km}$ in winter and $\sim 70-75 \mathrm{~km}$ in summer. Voigt line widths are lowest in the lower thermosphere at $\sim 95-100 \mathrm{~km}$, with minimum FWHM of $17 \mathrm{kHz}$ for $\mathrm{O}_{3}$ and $34 \mathrm{kHz}$ for $\mathrm{OH}$, and the line widths increase above $100 \mathrm{~km}$ due to increased Doppler broadening. Forward model spectra were therefore calculated with a frequency grid spacing of $10 \mathrm{kHz}$ over a bandwidth of $1 \mathrm{MHz}$ to encompass the range of emission line widths from $\mathrm{O}_{3}$ and 
(a) $\mathrm{O}_{3} 11.072 \mathrm{GHz}$

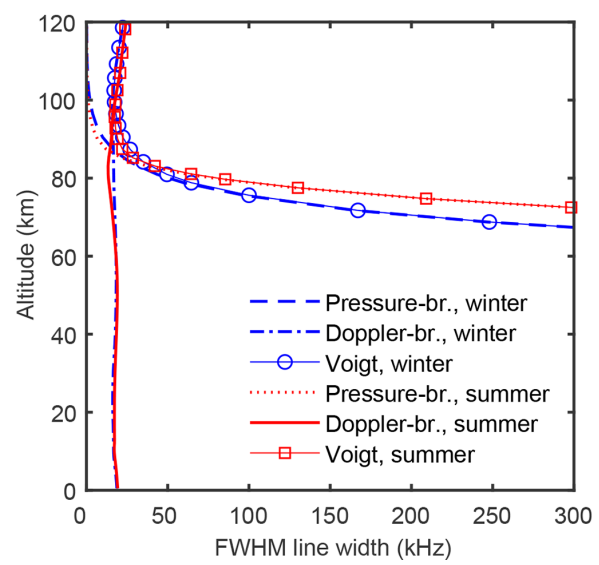

(b) $\mathrm{OH} 13.441 \mathrm{GHz}$

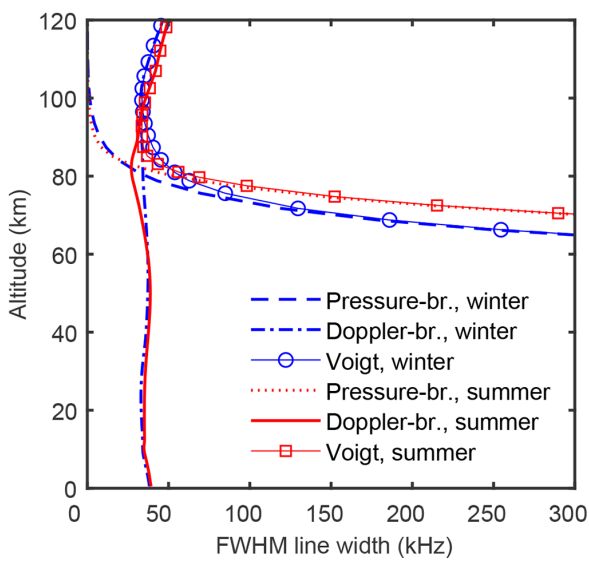

Figure 4. Pressure-broadened, Doppler-broadened, and Voigt full-width half-maxima (FWHM) line widths for $\left(\right.$ a) ozone $\left(\mathrm{O}_{3}\right) 11.072 \mathrm{GHz}$ and (b) $\mathrm{OH} 13.441 \mathrm{GHz}$ emission lines, calculated for mean winter (DJF) and mean summer (JJA) conditions at Kilpisjärvi (69 $03^{\circ} \mathrm{N}$, $20^{\circ} 48^{\prime}$ E), Finland.

$\mathrm{OH}$ in the mesosphere and lower thermosphere. All measurement simulations were performed for a single pencil beam of radiation at a zenith angle of $82^{\circ}$.

An important consideration in our calculations is that $\mathrm{O}_{3}$ and $\mathrm{OH}$ atmospheric spectra can be measured over $6 \mathrm{~h}$ with rms baseline noise of $1.0 \mathrm{mK}$, and this assumption is justified as follows. Low-cost LNB receivers with a noise factor of $\sim 1.3 \mathrm{~dB}$ currently used in $\mathrm{O}_{3} 11.072 \mathrm{GHz}$ spectrometers for the educational project Mesospheric Ozone System for Atmospheric Investigations in the Classroom (MOSAIC) operate uncooled, i.e. at ambient temperature (Rogers et al., 2012). By analysing signals from both horizontal and vertical polarisation channels of the LNB with $10 \mathrm{kHz}$ frequency resolution, and integrating the atmospheric signal for $24 \mathrm{~h}$, an atmospheric spectrum with baseline noise of $\sim 3.4 \mathrm{mK}$ is achieved. The statistical fluctuation $\Delta T(\mathrm{~K})$ in the total system temperature, $T_{\text {sys }}(\mathrm{K})$, is calculated according to the ideal radiometer equation (Kraus, 1986):

$\Delta T=\frac{T_{\mathrm{sys}}}{\sqrt{t \Delta f N_{\mathrm{CH}}}}$,

where $t$ is observation time (in seconds), $\Delta f$ is the frequency resolution (in hertz) of the radiometer, and $N_{\mathrm{CH}}$ is the number of measurement channels. Applying this equation we can define the sensor characteristics needed to achieve a signalto-noise ratio of $1.0 \mathrm{mK}$ in $6 \mathrm{~h}$ measurements, providing adequate time resolution to observe predicted changes in mesospheric $\mathrm{O}_{3}$ and $\mathrm{OH}$. The results in Table 1 show that higherperformance LNB receivers, with a noise of factor $0.7 \mathrm{~dB}$, would achieve such measurements of the $\mathrm{O}_{3} 11.072 \mathrm{GHz}$ emission if cooled to $168 \mathrm{~K}$. Alternatively, an array of 12 receivers operating at room temperature, with a total of 24 measurement channels, would achieve this measurement performance. At the higher frequency $(13.441 \mathrm{GHz})$ of the $\mathrm{OH}$ emission, available LNBs are less sensitive, with a noise fac- tor of $1.2 \mathrm{~dB}$, and would require cryogenic operation at $46 \mathrm{~K}$ to achieve the equivalent performance. A receiver array at room temperature would need 40 spectrometers (i.e. 80 measurement channels) to achieve the required measurement performance at $13.441 \mathrm{GHz}$. Thus we conclude that suitable receivers could be constructed using commercially available LNB receivers, albeit with the added complexity and higher power consumption needed for low-temperature operation or, alternatively, by combining the outputs from multiple room temperature receivers to achieve higher signal-to-noise spectra.

The treatment of the Zeeman effect in the Stokes formalism of ARTS is described by Larsson et al. (2014). The Zeeman components of the $\mathrm{OH}$ line centred at $13.441 \mathrm{GHz}$ were calculated for an instrument viewing at an azimuthal angle of $0^{\circ}$ i.e. northward-looking from Kilpisjärvi, with sensor polarisation being vertical, horizontal, or in both directions combined. Magnetic field data were taken from IGRF-11 (Finlay et al., 2010) and the Faddeeva function was used to describe the line shape.

Forward model spectra were calculated for ground-based clear-sky observations during December substorm and background (no substorm) conditions at Kilpisjärvi. The emission signals from different altitudes were found by selectively setting $\mathrm{O}_{3}$ and $\mathrm{OH}$ VMR to zero for $10 \mathrm{~km}$ sections of the mesosphere and lower thermosphere, and also running simulations with zero $\mathrm{O}_{3}$ and $\mathrm{OH}$ VMR at all altitudes. In order to assess measurement uncertainties in the retrieval algorithm and its ability to reproduce the "true" state of the atmosphere, two sets of 500 spectra each of $\mathrm{O}_{3}$ and $\mathrm{OH}$ were calculated for Monte Carlo (MC) error analysis. In one set of $\mathrm{MC}$ repeat spectra all VMR profiles were kept constant at the true values whereas in the other set the $\mathrm{O}_{3}, \mathrm{OH}$, and $\mathrm{H}_{2} \mathrm{O}$ profiles were randomly scaled using a uniform distribution over the range $0.5-2.0$. Baseline noise with a rms level of $1.0 \mathrm{mK}$ was 
Table 1. Calculated performance for ozone $\left(\mathrm{O}_{3}\right) 11.072 \mathrm{GHz}$ and hydroxyl $(\mathrm{OH}) 13.441 \mathrm{GHz}$ radiometers with $10 \mathrm{kHz}$ frequency resolution.

\begin{tabular}{lrrrr|rrr}
\hline & \multicolumn{3}{c}{$\mathrm{O}_{3} 11.072 \mathrm{GHz}$} & & $\mathrm{OH}$ & $13.441 \mathrm{GHz}$ \\
\hline Noise factor (dB) & 1.3 & 0.7 & 0.7 & 0.7 & 1.2 & 1.2 & 1.2 \\
Reference temperature (K) & 290 & 290 & 290 & 168 & 290 & 290 & 46 \\
System noise temperature (K) & 101 & 51 & 51 & 15 & 92 & 92 & 15 \\
Number of measurement channels & 2 & 2 & 24 & 2 & 2 & 80 & 2 \\
Measurement time (h) & 24 & 24 & 6 & 6 & 24 & 6 & 6 \\
$1 \sigma$ rms noise (K) & 3.4 & 1.7 & 1.0 & 1.0 & 3.1 & 1.0 & 1.0 \\
\hline
\end{tabular}

randomly calculated and added to each individual $\mathrm{O}_{3}$ and $\mathrm{OH}$ spectrum in both of the MC sets.

\subsection{Retrievals}

The $6 \mathrm{~h}$ atmospheric spectra, simulated for December substorm and background (no substorm) conditions at Kilpisjärvi, were inverted into altitude profiles of $\mathrm{O}_{3}$ and $\mathrm{OH}$ VMR using the optimal estimation method (OEM) (Rodgers, 2000) implemented in Qpack (Eriksson et al., 2005). Iterative absorption calculations in ARTS were performed line by line within the radiative transfer calculation, rather than using precalculated look-up tables, in order to accurately model atmospheric spectra (Buehler et al., 2011). VMR values were retrieved for altitude levels $0-120 \mathrm{~km}$ with a $1 \mathrm{~km}$ spacing, for which hydrostatic equilibrium was assumed for the altitude and pressure. The $\mathrm{O}_{3}, \mathrm{OH}$, and $\mathrm{H}_{2} \mathrm{O}$ a priori VMR profiles were the December monthly mean profiles for Kilpisjärvi. The diagonal elements in the covariance of the $\mathrm{O}_{3}$ and $\mathrm{OH}$ a priori VMR profiles were fixed to $1.5 \mathrm{ppmv}$ and $10 \mathrm{ppbv}$ respectively, whereas for $\mathrm{H}_{2} \mathrm{O}$ they were fixed at the square of $50 \%$ of the VMR values. The off-diagonal elements of the covariance linearly decrease with a correlation length of a fifth of a pressure decade (approximately $3 \mathrm{~km}$ ).

\section{Results}

\subsection{Simulated atmospheric spectra}

Survey clear-sky atmospheric transmittance spectra, calculated for the selected locations, are shown in Fig. 5. Water vapour absorption leads to decreased transmittance at frequencies above $10 \mathrm{GHz}$. Higher transmittance occurs for the three colder, desiccated Antarctic sites whereas the generally milder NH locations have lower transmittance, especially in summertime. Considering the frequencies of the $\mathrm{O}_{3}$ and $\mathrm{OH}$ lines, at a zenith angle of $0^{\circ}$, transmittance is 0.98 at the six locations in both winter and summer conditions. At a zenith angle of $82^{\circ}$ the lower transmittance, in the range $0.84-0.86$, is due to the higher air mass factor and increased tropospheric attenuation in particular by water vapour, oxygen, and nitrogen continua. However, the very similar transmittances at various locations suggest that the different seasonal me- teorology should have little impact on the proposed $\mathrm{O}_{3}$ and $\mathrm{OH}$ observations, unlike ground-based measurements using higher frequencies in the millimetre-wave region where cold, dry, high-altitude sites are advantageous.

Forward model simulations of the $\mathrm{O}_{3} 11.072 \mathrm{GHz}$ emission line are shown in Fig. 6a and b, for the substorm and background (no substorm) cases respectively. The solid black lines in each plot are the brightness temperature spectra that would be observed at the ground in clear-sky conditions at a zenith angle of $82^{\circ}$. The other lines show the contributions to the total signal from $10 \mathrm{~km}$ layers in the mesosphere and lower thermosphere between 50 and $110 \mathrm{~km}$. For the substorm scenario, $\mathrm{O}_{3}$ emission is reduced around the peak at $11.072 \mathrm{GHz}$ compared to the background case. The largest decrease in signal corresponds to altitudes $70-80 \mathrm{~km}$, where the modelled reduction in $\mathrm{O}_{3}$ number density during substorms is greatest, with smaller decreases at $60-70$ and 80 $90 \mathrm{~km}$

Forward model simulations of the $\mathrm{OH} 13.441 \mathrm{GHz}$ emission line are shown in Fig. 7a-f. Figure 7a, c, and e are the substorm spectra for three different sensor polarisations: both polarisations, vertical, and horizontal respectively. Figure $7 \mathrm{~b}$, $\mathrm{d}$, and $\mathrm{f}$ show the corresponding spectra for the background (no substorm) case. The solid black lines in each plot are the brightness temperature spectra that would be observed at the ground in clear-sky conditions at a zenith angle of $82^{\circ}$. The other lines are the contribution to the total signal from $10 \mathrm{~km}$ layers in the mesosphere and lower thermosphere between 50 and $100 \mathrm{~km}$. At an azimuthal angle of $0^{\circ}$ the vertical polarisation signal is dominated by a single line centred at $13.441 \mathrm{GHz}$ whereas in horizontal polarisation the pair of Zeeman split lines are clearly resolved. For the substorm scenario, $\mathrm{OH}$ emission increases around the peak positions compared to the background case. As for $\mathrm{O}_{3}$, the largest changes in signal correspond to altitudes of $70-80 \mathrm{~km}$, where the modelled increase in $\mathrm{OH}$ number density during substorms is greatest, with smaller increases at $80-90 \mathrm{~km}$.

\subsection{Ozone retrievals}

Example retrieval results are shown in Figs. 8 and 9 for simulated clear-sky $6 \mathrm{~h}$ observations of the $\mathrm{O}_{3} 11.072 \mathrm{GHz}$ line at an $82^{\circ}$ zenith angle from Kilpisjärvi in December substorm and background conditions using a radiometer provid- 


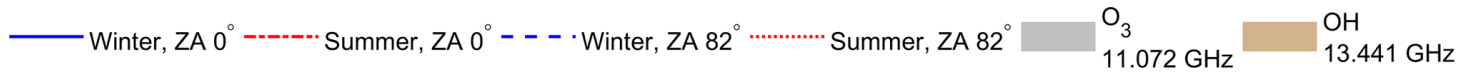

(a) Halley, Antarctica

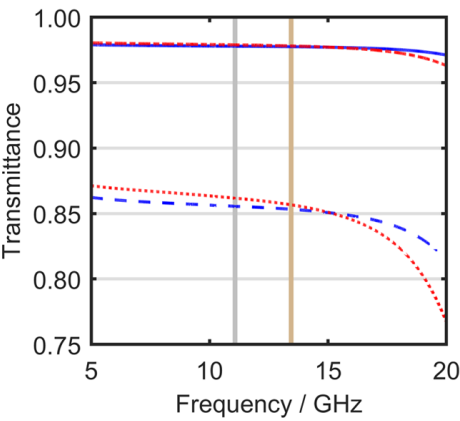

(d) Kilpisjarvi, Finland

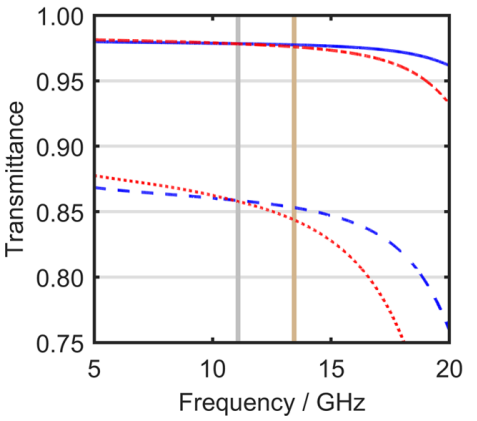

(b) Syowa, Antarctica

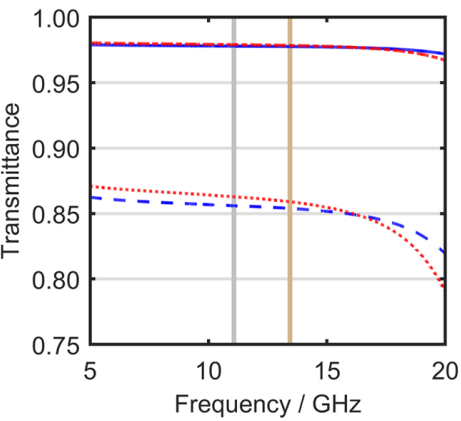

(e) Reykjavik, Iceland

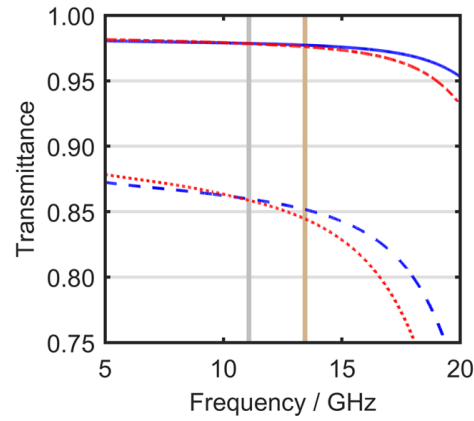

(c) Pillow Knob, Antarctica

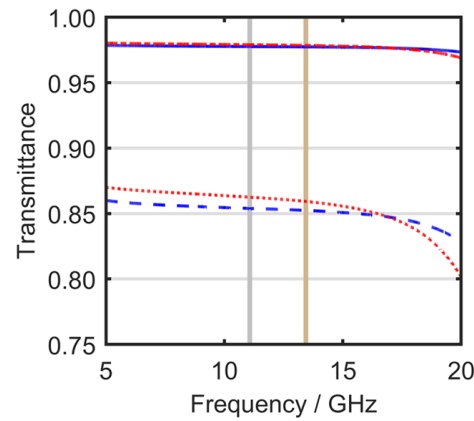

(f) Fairbanks, Alaska

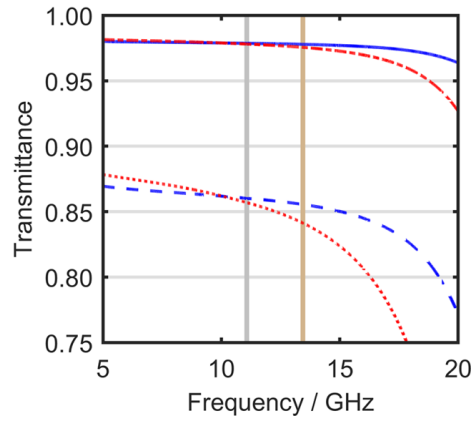

Figure 5. Survey atmospheric transmittance spectra at six polar locations for the frequency range 5-20 GHz, calculated on a $1 \mathrm{MHz}$ frequency grid. In panels (a)-(c) transmittances calculated at zenith angles (ZAs) of $0^{\circ}$ (i.e. viewing vertically upwards) and $82^{\circ}$ are shown for mean summer (DJF) and mean winter (JJA) conditions at three Antarctic locations. In panels (d)-(f) transmittances calculated at ZAs of 0 and $82^{\circ}$ are shown for mean summer (JJA) and mean winter (DJF) conditions at three Arctic locations. The light grey and light brown vertical lines indicate the frequencies of the ozone $\left(\mathrm{O}_{3}, 11.072 \mathrm{GHz}\right)$ and hydroxyl $(\mathrm{OH}, 13.441 \mathrm{GHz})$ emission lines.

(a) Background (no substorm)

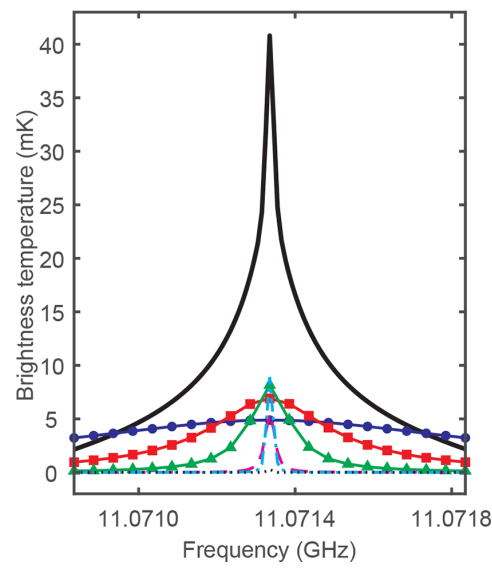

(b) Substorm

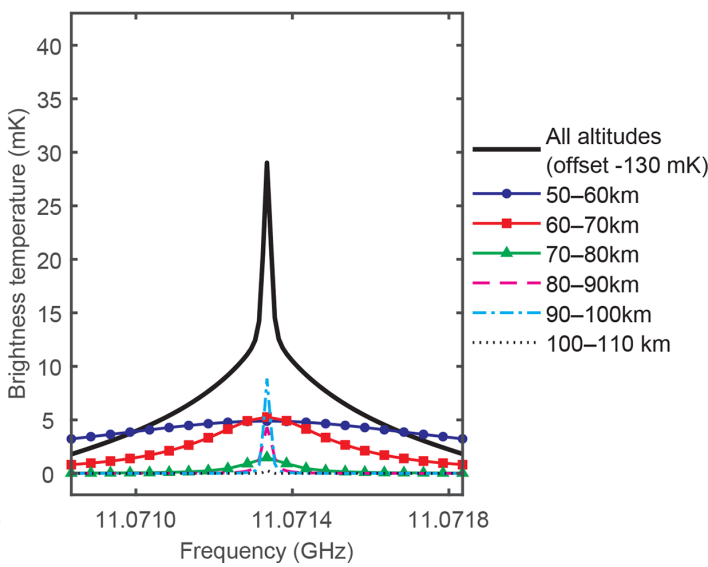

Figure 6. Simulated atmospheric spectra for the ozone $\left(\mathrm{O}_{3}\right) 11.072 \mathrm{GHz}$ emission line in clear-sky December conditions using a groundbased radiometer with $10 \mathrm{kHz}$ frequency resolution, $82^{\circ}$ zenith angle, and $0^{\circ}$ azimuthal angle located at Kilpisjärvi $\left(69^{\circ} 03^{\prime} \mathrm{N}, 20^{\circ} 48^{\prime} \mathrm{E}\right)$, Finland. Black solid curves show the overall $\mathrm{OH}$ emission from all altitudes. Coloured lines show the contributions from $10 \mathrm{~km}$ altitude intervals in the range 50-110 km. Panels (a) and (b) show the spectra for background (no substorm) and substorm conditions respectively. 

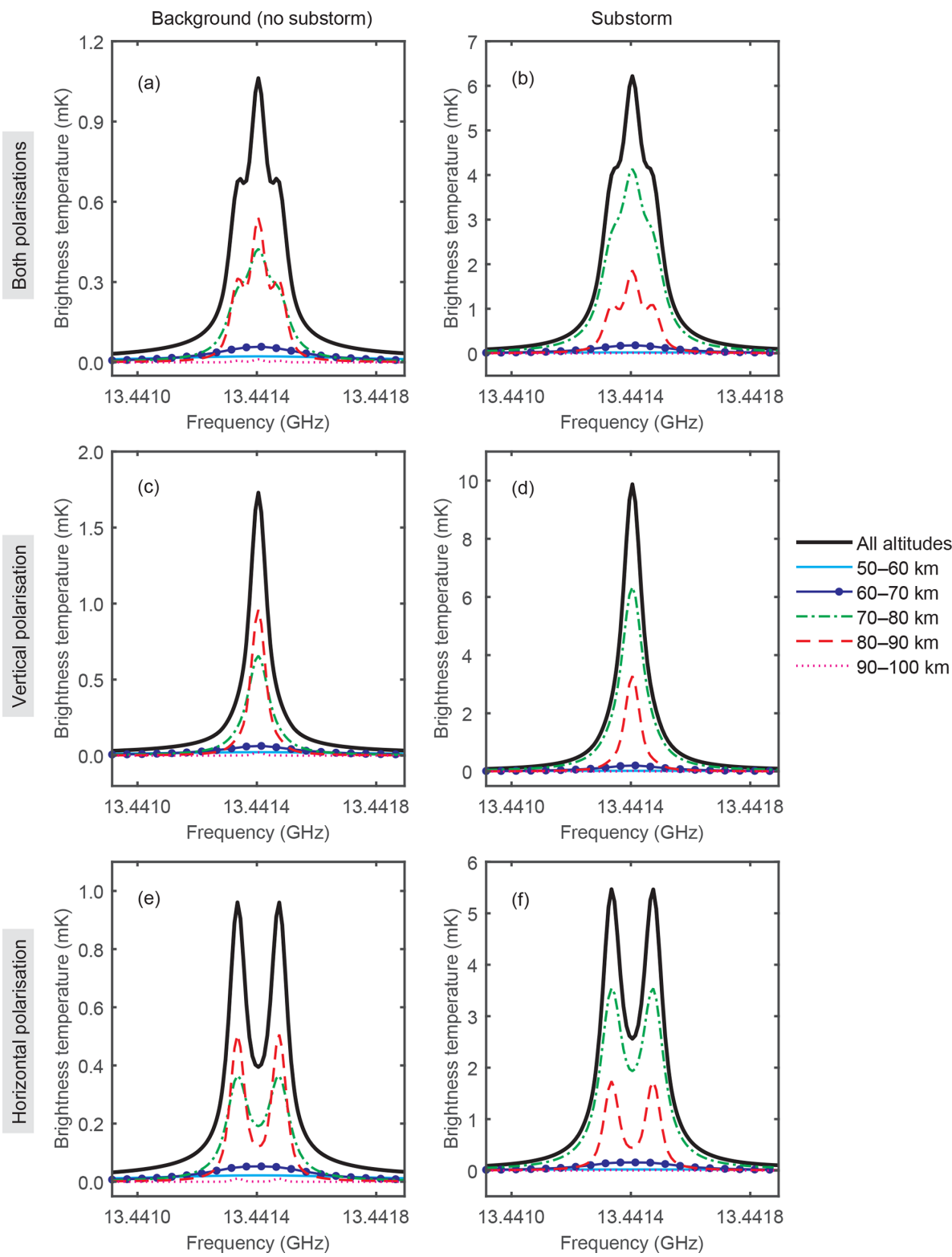

Figure 7. Simulated atmospheric spectra for the hydroxyl $(\mathrm{OH}) 13.441 \mathrm{GHz}$ emission line in clear-sky December conditions using a groundbased radiometer with $10 \mathrm{kHz}$ frequency resolution, $82^{\circ}$ zenith angle, and $0^{\circ}$ azimuthal angle located at Kilpisjärvi $\left(69^{\circ} 03^{\prime} \mathrm{N}, 20^{\circ} 48^{\prime} \mathrm{E}\right)$, Finland. Contributions from other atmospheric species have been removed to show changes in the brightness temperature spectra due to $\mathrm{OH}$. Black solid curves show the overall $\mathrm{OH}$ emission from all altitudes. Coloured lines show the contributions from $10 \mathrm{~km}$ altitude intervals in the range 50-100 km. Panels (a) and (b) are for all sensor polarisations in background (no substorm) and substorm conditions respectively. Similarly, (c) and (d) are for vertical sensor polarisation and (e) and (f) are for horizontal sensor polarisation.

ing $10 \mathrm{kHz}$ frequency resolution. Figure $8 \mathrm{a}$ and e show the final retrieval fits, for the substorm and background cases respectively, which agree with the simulated atmospheric spectra to within the rms baseline noise level. Figure $8 \mathrm{c}$ and $\mathrm{g}$ compare the true and a priori $\mathrm{O}_{3}$ VMR profiles with the retrieved profiles for the substorm and background cases respectively. The red solid lines and red shaded areas show the average and standard deviations of the retrieved profiles from 500 repeat $\mathrm{MC}$ runs with the $\mathrm{O}_{3}$ and $\mathrm{H}_{2} \mathrm{O}$ profiles used to calculate the spectra, shown by the blue dashed lines, kept constant at the true model values. For both the substorm and background cases the retrieved $\mathrm{O}_{3}$ profiles converge close to the true profiles over the altitudes where information is obtained from the observations, shown by the thicker solid lines and grey shaded areas. The description of how the retrieval altitude range is determined is given in the next paragraph. The differences between the retrieved and true VMR profiles, shown in Fig. $8 \mathrm{~d}$ and $\mathrm{h}$, are in the range -1.0 to $0.9 \mathrm{ppmv}$. 
Above and below the retrieval range the $\mathrm{O}_{3}$ profiles tend towards the a priori values.

The averaging kernels (AVKs) for every sixth retrieved altitude are shown in Fig. 9a. The AVKs describe the relationship among the true, a priori, and retrieved atmospheric states (Rodgers, 2000). None of the AVKs peak at pressure levels above $0.0013 \mathrm{hPa}(\sim 94 \mathrm{~km})$ due to Doppler broadening dominating over pressure broadening. The lowest AVK peaks are at $0.18 \mathrm{hPa}(\sim 60 \mathrm{~km})$. The sum of the AVKs at each altitude, called the measurement (or total) response (MR), represents the extent to which the measurement contributes to the retrieval solution compared to the influence of the a priori at that altitude (Christensen and Eriksson, 2013). The altitude range where the retrieved $\mathrm{O}_{3}$ profile has a high degree of independence from the a priori is identified by MR values higher than 0.8 . The retrieval altitude range is $8 \times 10^{-4}$ $0.22 \mathrm{hPa}(\sim 98-58 \mathrm{~km})$, shown by the thicker sections of the lines and the grey shaded areas in Figs. 8 and 9. Outside of these altitudes (i.e. below 58 and above $98 \mathrm{~km}$ ) the MR weakens and the $\mathrm{O}_{3}$ values in these regions should be interpreted with caution as the information from the a priori becomes important. The AVKs indicate the range of altitudes over which $\mathrm{O}_{3}$ is observed. In the ideal case the AVKs would be delta functions but in practice they are peaked functions with finite widths dependent on the spatial resolution of the observing system. The FWHM widths of the kernels provide a measure of the vertical resolution of the retrieved profile. The FWHM values shown in Fig. 9b indicate altitude resolutions decreasing from $10.9 \mathrm{~km}$ in the lower mesosphere to $18.4 \mathrm{~km}$ in the upper mesosphere and lower thermosphere, at altitudes below $98 \mathrm{~km}$. The altitude resolution can also be estimated from the degrees of freedom for signal (DOFS) for the inversion, given by the trace of the AVK matrix (Rodgers, 2000; Ryan et al., 2016). Dividing the retrieved altitude range $(\sim 30 \mathrm{~km})$ by the DOFS over the same range $(\sim 3.2)$ gives an altitude resolution of $12.0 \mathrm{~km}$, similar to that obtained from the AVK FWHM values.

The OEM calculations provide observation errors $\left(\sigma_{\text {obs }}\right)$ and total retrieval (observation plus smoothing) errors $\left(\sigma_{\text {tot }}\right)$, which provide further diagnostic uncertainty estimates of the retrieved profiles. The observation errors describe how the retrieved profiles are affected by measurement noise and are shown in Fig. 9c, with typical values of about 0.34 ppmv. The observation errors are small outside of the range of the AVK peaks as the retrieval tends to the a priori values in these regions and the contribution from the measurement is small. The total retrieval errors shown in Fig. 9d are in the range $1.09-1.34$ ppmv and tend towards the smaller a priori standard deviations outside the range of AVK peaks.

The results of the MC error analysis using retrievals from 500 simulated spectra in which $\mathrm{O}_{3}$ and $\mathrm{H}_{2} \mathrm{O}$ profiles were randomly scaled using a uniform distribution over the range $0.5-2.0$, to test the retrieval algorithm's ability to reproduce the true state of the atmosphere, are shown in Fig. 9e-f. Over the trustable altitude range the mean difference $\left(\mu_{\mathrm{MC}}\right)$ be- tween the $\mathrm{MC}$ retrieved and true profiles is in the range from -0.8 to $2.0 \mathrm{ppmv}$. The standard deviation $\left(\sigma_{\mathrm{MC}}\right)$ of the individual retrievals is an estimator for the uncertainty of the $\mathrm{O}_{3}$ retrieval, and the mean value of $0.8 \mathrm{ppmv}$ is approximately double the mean observation error determined from single retrievals $\left(\sigma_{\mathrm{obs}}\right)$. Both parameters depend on the signal-tonoise ratio of the input spectrum but $\sigma_{\mathrm{MC}}$ may more realistically represent actual observations in which mesospheric $\mathrm{O}_{3}$ profiles and column $\mathrm{H}_{2} \mathrm{O}$ show large variability.

The Jacobian and gain matrices of the $\mathrm{O}_{3}$ forward model indicate that an instrument with $10 \mathrm{kHz}$ frequency resolution will adequately sample the emission line for altitudes of up to $\sim 98 \mathrm{~km}$ where the $\mathrm{O}_{3}$ measurement contributes significantly to the retrieval. The values of the Jacobian, normalised by the layer thickness of the retrieval grid for observations at an $82^{\circ}$ zenith angle are shown in Fig. 10. Typical values of the Jacobian are $\sim 0.5 \mathrm{mK}(\mathrm{ppmv})^{-1} \mathrm{~km}^{-1}$ at mesospheric altitudes of $60-90 \mathrm{~km}$ where substorms are predicted to have the largest effect on $\mathrm{O}_{3}$ abundance. The effect of predicted $\mathrm{O}_{3}$ changes of $\sim 1$ ppmv over altitudes of $68-86 \mathrm{~km}$ on the measured atmospheric brightness temperature will therefore be small, of the order of $9 \mathrm{mK}$ close to the emission line centre, but readily measurable with a baseline noise of $1 \mathrm{mK}$ for a $6 \mathrm{~h}$ integration.

\subsection{Hydroxyl $(\mathrm{OH})$ retrievals}

Example retrieval results are shown in Figs. 11 and 12 for simulated clear-sky $6 \mathrm{~h}$ observations of the $\mathrm{OH} 13.441 \mathrm{GHz}$ line at an $82^{\circ}$ zenith angle and $0^{\circ}$ azimuthal angle from Kilpisjärvi in December substorm conditions using a radiometer providing $10 \mathrm{kHz}$ frequency resolution with vertical sensor polarisation. Similar results were obtained for retrievals with simulated spectra using sensors measuring horizontal or both polarisations, and with non-zero azimuthal angles. Figure 11a and $\mathrm{b}$ show the final retrieval fits which agree with the simulated atmospheric spectra to within the rms baseline noise level. Figure 11c and d compare the true substorm and a priori OH VMR profiles with the retrieved profiles. The red solid lines and red shaded areas show the average and standard deviation of the retrieved profiles from 500 repeat $\mathrm{MC}$ runs with the $\mathrm{OH}$ and $\mathrm{H}_{2} \mathrm{O}$ profiles used to calculate the spectra, shown by the dashed blue lines, kept constant at the true model values. The retrieved $\mathrm{OH}$ profile approaches the true profiles over the altitudes where information is obtained from the observations, shown by the thicker solid lines and grey shaded areas. However, Fig. 11d shows significant differences, in the range from -13.6 to $3.3 \mathrm{ppbv}$, between the retrieved and true VMR profiles at altitudes which overlap the $\mathrm{OH}$ enhancements. Convolving the true $\mathrm{OH}$ profile with the averaging kernels, to account for the limited retrieval resolution, results in much better agreement with differences $\left(R-T^{*}\right)$ in the range from -1.4 to 2.9 ppbv. Above and below the retrieval range the $\mathrm{OH}$ pro- 

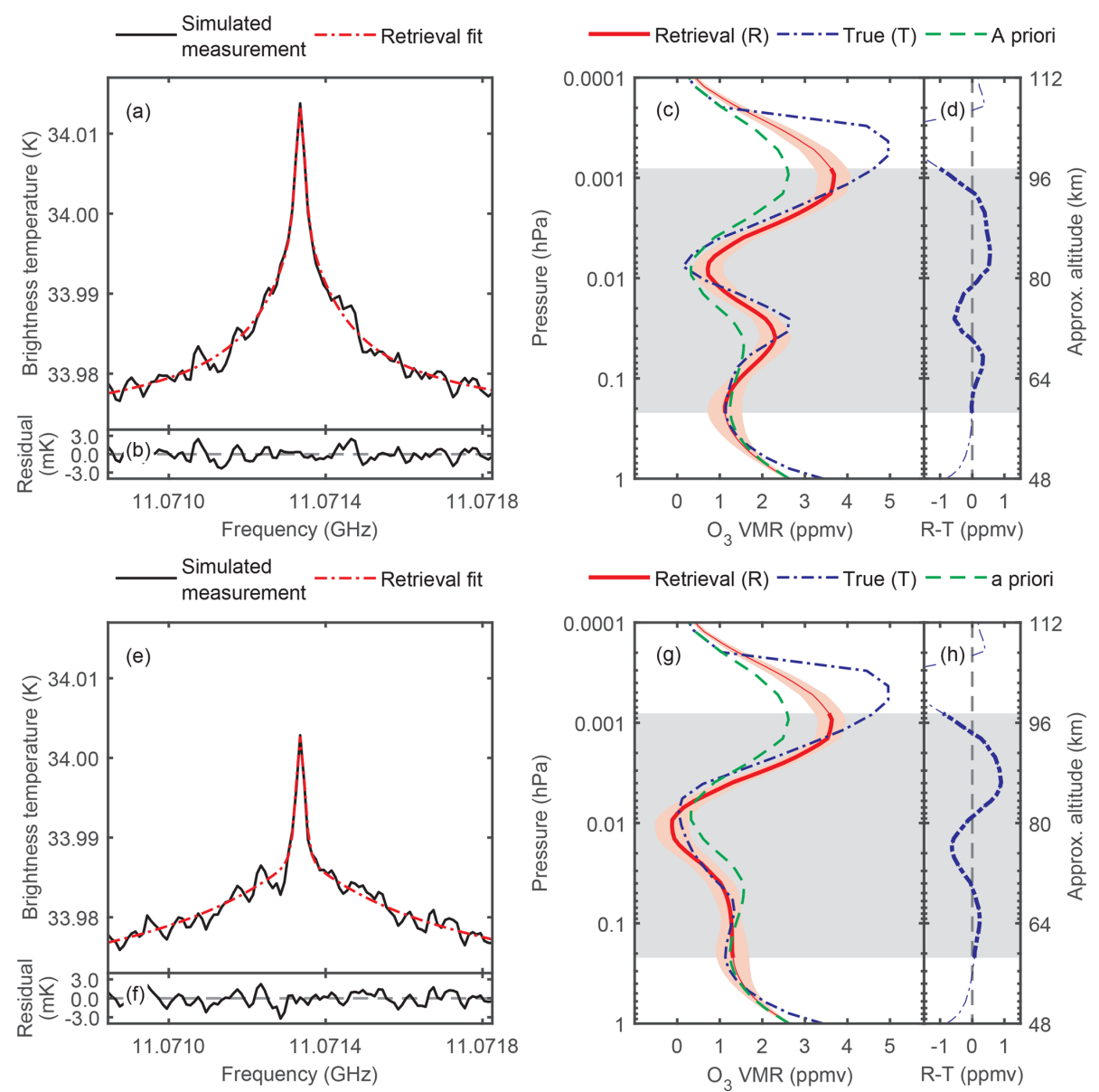

Figure 8. Ozone $\left(\mathrm{O}_{3}\right)$ retrievals for simulated $6 \mathrm{~h}$ observations of the $\mathrm{O}_{3} 11.072 \mathrm{GHz}$ emission line in clear-sky December conditions using a ground-based radiometer at Kilpisjärvi $\left(69^{\circ} 03^{\prime} \mathrm{N}, 20^{\circ} 48^{\prime} \mathrm{E}\right)$, Finland. The forward model clear-sky spectra are calculated using the model $\mathrm{O}_{3}$ profiles for December 2007 with $1 \mathrm{mK}$ baseline noise, $10 \mathrm{kHz}$ frequency resolution, and an $82^{\circ}$ zenith angle. Panels (a)-(d) show the results using background (no substorm) $\mathrm{O}_{3}$ in the simulations, and (e)-(g) show the results for substorm $\mathrm{O}_{3}$. The simulated $\mathrm{O}_{3}$ spectra and retrieval fits are shown in (a) and (e), and the residual differences are shown in (b) and (f). The a priori, true, and retrieved $\mathrm{O}_{3}$ volume mixing ratio profiles, and the differences between the retrieved and true profiles, are shown in (c)-(d) and (g)-(h) for the background and substorm cases respectively.

files approach the a priori OH VMR values, which are close to zero.

The AVKs for every sixth retrieved altitude are shown in Fig. 12a. None of the AVKs peak at pressure levels above $0.003 \mathrm{hPa}(\sim 88 \mathrm{~km})$ due to Doppler broadening dominating over pressure broadening. The lowest AVK peaks at $0.24 \mathrm{hPa}$ $(\sim 58 \mathrm{~km})$. The estimated retrieval range, where the MR is larger than 0.8 , is $3 \times 10^{-3}-0.29 \mathrm{hPa}(\sim 90-56 \mathrm{~km})$, shown by the thicker sections of the lines and the grey shaded areas in Figs. 11 and 12. Outside of these altitudes (i.e. below 56 and above $90 \mathrm{~km}$ ) the MR weakens and the $\mathrm{OH}$ values in these regions should be interpreted with caution as the information from the a priori becomes important. The AVK FWHM values shown in Fig. 12b indicate altitude resolutions decreasing from $10.2 \mathrm{~km}$ in the lower mesosphere to $16.6 \mathrm{~km}$ in the upper mesosphere, at altitudes below $90 \mathrm{~km}$. Dividing the retrieved altitude range $(\sim 34 \mathrm{~km})$ by the DOFS over the same range $(\sim 3.0)$ gives an estimated altitude resolution of $11.0 \mathrm{~km}$, similar to that obtained from the AVK FWHM values. The observation errors $\left(\sigma_{\mathrm{obs}}\right)$ shown in Fig. 12c have typical values of $2.1 \mathrm{ppbv}$ and are smaller outside of the range of the AVK peaks as the retrieval tends to the a priori values in these regions and the contribution from the measurement is small. The total retrieval errors $\left(\sigma_{\mathrm{tot}}\right)$ shown in Fig. $12 \mathrm{~d}$ are in the range 7.1-9.0 ppbv and tend towards the larger a priori standard deviations when they are outside the range of AVK peaks.

The results of the $\mathrm{MC}$ error analysis using retrievals from 500 simulated spectra in which $\mathrm{OH}$ and $\mathrm{H}_{2} \mathrm{O}$ profiles were randomly scaled by $0.5-2.0$ are shown in Fig. $12 \mathrm{e}-\mathrm{f}$. Over the trustable altitude range the mean difference $\left(\mu_{\mathrm{MC}}\right)$ between the MC retrieved and true profiles is in the range from -1.4 to $1.6 \mathrm{ppbv}$. The standard deviation $\left(\sigma_{\mathrm{MC}}\right)$ of the individual retrievals is an estimator for the uncertainty of the $\mathrm{OH}$ 


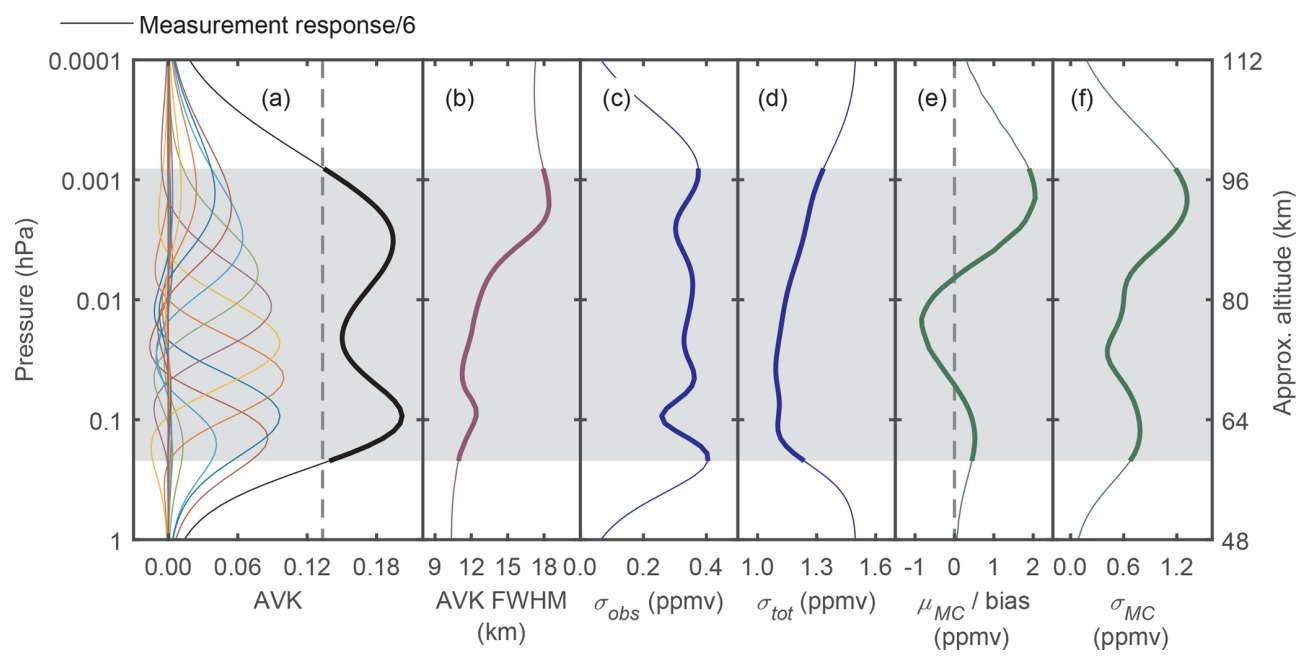

Figure 9. Ozone $\left(\mathrm{O}_{3}\right)$ retrieval diagnostics for simulated $6 \mathrm{~h}$ observations of the $\mathrm{O}_{3} 11.072 \mathrm{GHz}$ emission line using a ground-based radiometer with $1 \mathrm{mK}$ baseline noise level, $10 \mathrm{kHz}$ frequency resolution, and an $82^{\circ}$ zenith angle located at Kilpisjärvi $\left(69^{\circ} 03^{\prime} \mathrm{N}, 20^{\circ} 48^{\prime} \mathrm{E}\right)$, Finland, in clear-sky December conditions. In (a) every sixth averaging kernel and the scaled measurement response (MR) are shown. Panel (b) shows the full-width half maxima of each averaging kernel (AVK FWHM). The measurement uncertainty $\left(\sigma_{\mathrm{obs}}\right)$ and total uncertainty $\left(\sigma_{\text {tot }}\right)$ are shown in $(\mathbf{c})$ and $(\mathbf{d})$ respectively. The mean $\left(\mu_{\mathrm{MC}}\right)$ and standard deviation $\left(\sigma_{\mathrm{MC}}\right)$ of the differences between the retrieved and true profiles from Monte Carlo (MC) error analysis using 500 repeat inversions are shown in (e) and (f) respectively. The vertical grey dashed line in (a) shows the cut-off for $M R \geq 0.8$. The grey shaded regions and the thicker sections of the plotted curves indicate the pressure and altitude ranges where $\mathrm{MR} \geq 0.8$.
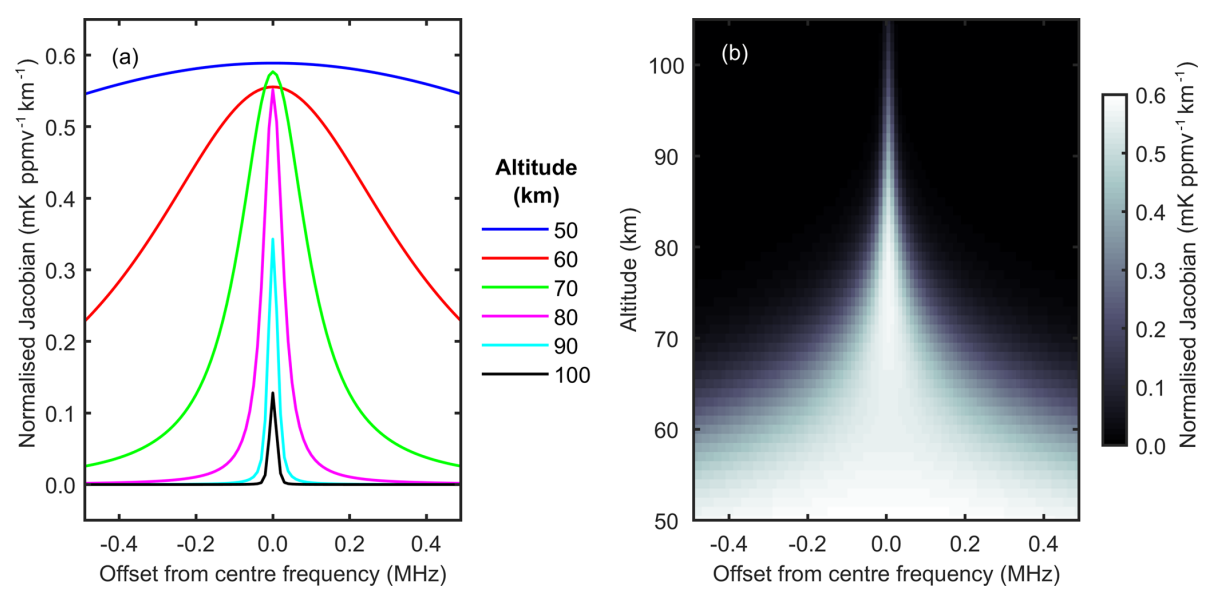

Figure 10. Rows of the Jacobian describing the ozone $\left(\mathrm{O}_{3}\right)$ retrieval, normalised by the layer thickness of the retrieval grid. The data are for retrievals from simulated $6 \mathrm{~h}$ observations of the $\mathrm{O}_{3} 11.072 \mathrm{GHz}$ emission line using a ground-based radiometer with $1 \mathrm{mK}$ baseline noise level, $10 \mathrm{kHz}$ frequency resolution, and an $82^{\circ}$ zenith angle located at Kilpisjärvi $\left(69^{\circ} 03^{\prime} \mathrm{N}, 20^{\circ} 48^{\prime} \mathrm{E}\right)$, Finland, in clear-sky December conditions. Rows of the Jacobian matrix for selected altitude levels are plotted in (a). The grey scale in (b) indicates the values of the Jacobian matrix.

retrieval, and the mean value of $2.6 \mathrm{ppbv}$ is similar the mean observation error determined from single retrievals $\left(\sigma_{\mathrm{obs}}\right)$. Both parameters depend on the signal-to-noise ratio of the input spectrum but $\sigma_{\mathrm{MC}}$ may more realistically represent actual observations in which mesospheric $\mathrm{OH}$ profiles and column $\mathrm{H}_{2} \mathrm{O}$ show large variability.

The Jacobian and gain matrices of the $\mathrm{OH}$ vertical polarisation forward model indicate that, as for $\mathrm{O}_{3}$, the $\mathrm{OH}$ emission line should be adequately sampled by an instrument with
$10 \mathrm{kHz}$ frequency resolution for all altitudes where the $\mathrm{OH}$ measurement contributes significantly to the retrieval. The values of the Jacobian, normalised by the layer thickness of the retrieval grid for observations at an $82^{\circ}$ zenith angle, are shown in Fig. 13. Typical values of the Jacobian are $\sim 0.09 \mathrm{mK}(\mathrm{ppbv})^{-1} \mathrm{~km}^{-1}$ at mesospheric altitudes of 60 $90 \mathrm{~km}$ where substorms are predicted to have the largest effect on $\mathrm{OH}$ abundance. The predicted changes in $\mathrm{OH} \mathrm{VMR}$, by up to $\sim 20 \mathrm{ppbv}$ for the altitude range $64-84 \mathrm{~km}$, will have 

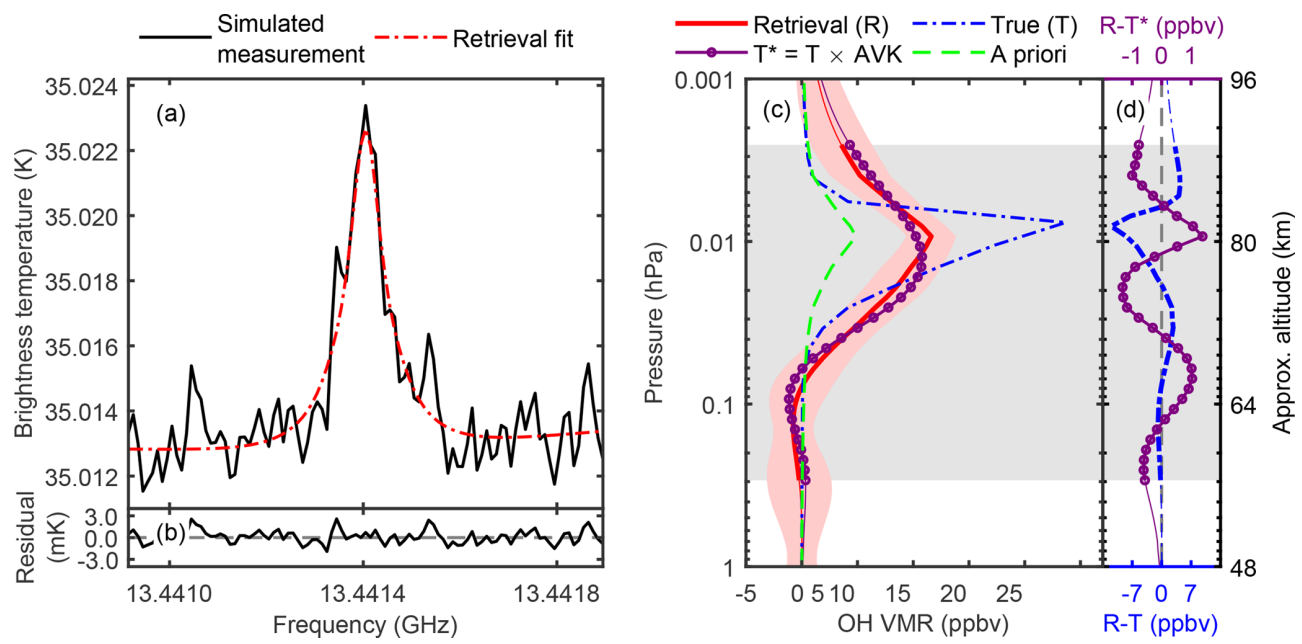

Figure 11. Hydroxyl $(\mathrm{OH})$ retrievals for simulated $6 \mathrm{~h}$ observations of the $\mathrm{OH} 13.441 \mathrm{GHz}$ emission line using a ground-based radiometer with vertical sensor polarisation at Kilpisjärvi $\left(69^{\circ} 03^{\prime} \mathrm{N}, 20^{\circ} 48^{\prime} \mathrm{E}\right)$, Finland. The forward model clear-sky spectrum is calculated using the model $\mathrm{OH}$ profile for substorm conditions in December 2007 with $1 \mathrm{mK}$ baseline noise, $10 \mathrm{kHz}$ frequency resolution, $82^{\circ}$ zenith angle, and $0^{\circ}$ azimuthal angle (i.e. north-pointing). The simulated $\mathrm{OH}$ spectra and retrieval fit are shown in (a), and the residual differences are shown in (b). The a priori, true, and retrieved $\mathrm{OH}$ volume mixing ratio profiles, and the differences between the retrieved and true profiles, are shown in (c) and (d). Note that the scales differ for the upper and lower axes of (d).

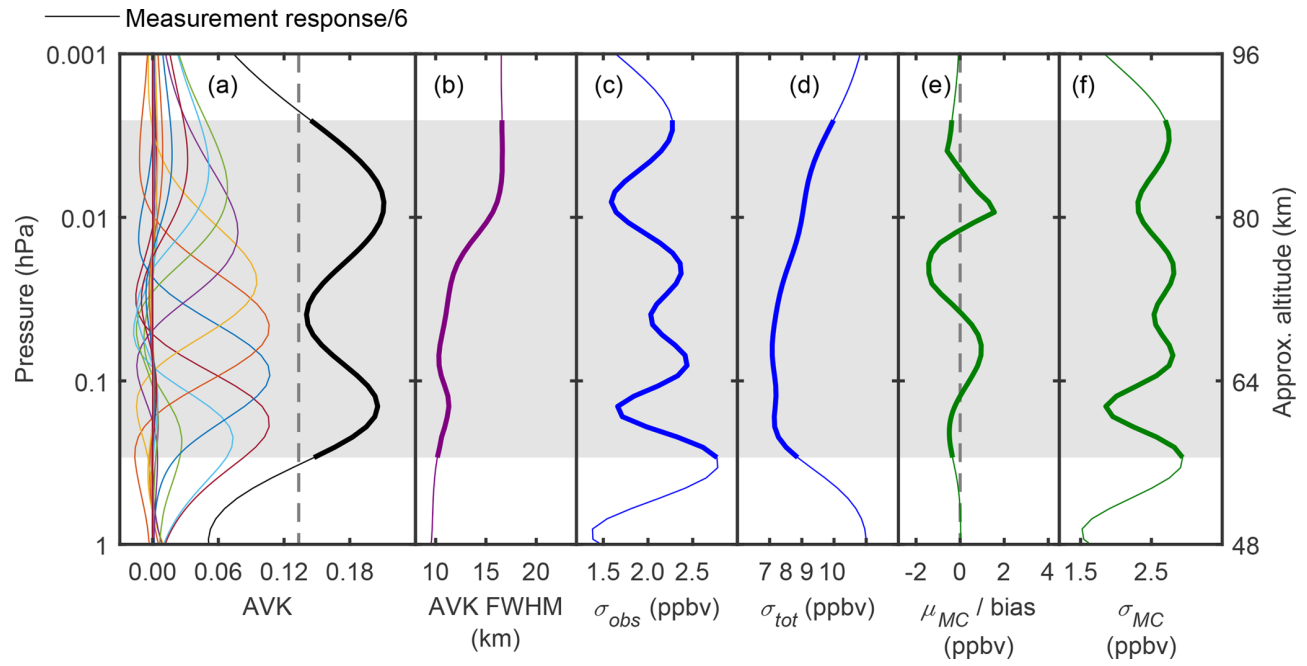

Figure 12. Hydroxyl $(\mathrm{OH})$ retrieval diagnostics for simulated $6 \mathrm{~h}$ observations of the $\mathrm{OH} 13.441 \mathrm{GHz}$ emission line using a ground-based radiometer with vertical polarisation, $1 \mathrm{mK}$ baseline noise level, $10 \mathrm{kHz}$ frequency resolution, $82^{\circ}$ zenith angle, and $0^{\circ}$ azimuthal angle (i.e. north-pointing) located at Kilpisjärvi $\left(69^{\circ} 03^{\prime} \mathrm{N}, 20^{\circ} 48^{\prime} \mathrm{E}\right)$, Finland, in clear-sky December conditions. In (a) every sixth averaging kernel and the scaled measurement response (MR) are shown. Panel (b) shows the full-width half maxima of each averaging kernel (AVK FWHM). The measurement uncertainty $\left(\sigma_{\mathrm{obs}}\right)$ and total uncertainty $\left(\sigma_{\mathrm{tot}}\right)$ are shown in (c) and (d) respectively. The mean $\left(\mu_{\mathrm{MC}}\right)$ and standard deviation $\left(\sigma_{\mathrm{MC}}\right)$ of the differences between the retrieved and true profiles from Monte Carlo (MC) error analysis using 500 repeat inversions are shown in (e) and (f) respectively. The vertical grey dashed line in (a) shows the cut-off for MR $\geq 0.8$. The grey shaded regions and the thicker sections of the plotted curves indicate the pressure and altitude ranges where $\mathrm{MR} \geq 0.8$.

a small effect on the measured atmospheric brightness temperatures, producing a $\sim 10 \mathrm{mK}$ increase close to the emission line centre. However, the enhanced $\mathrm{OH}$ microwave signal during substorm activity would be measurable with a baseline noise of $1 \mathrm{mK}$ for a $6 \mathrm{~h}$ integration.

\section{Conclusions}

The proof-of-concept simulations demonstrate that changes in $\mathrm{O}_{3}$ and $\mathrm{OH}$ abundance in the high-latitude or polar middle and upper atmosphere, associated with geomagnetic substorm and other EEP processes, could be profiled using 

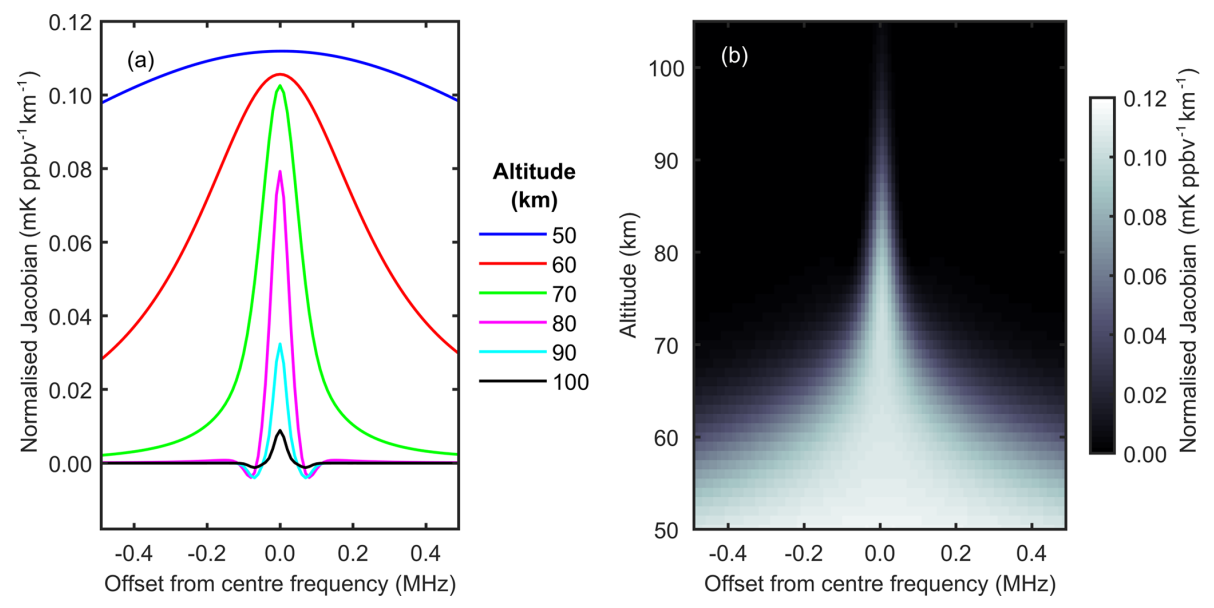

Figure 13. Rows of the Jacobian describing the hydroxyl $(\mathrm{OH})$ retrieval, normalised by the layer thickness of the retrieval grid. The data are for retrievals from simulated $6 \mathrm{~h}$ observations of the $\mathrm{OH} 13.441 \mathrm{GHz}$ emission line using a ground-based radiometer with vertical polarisation, $1 \mathrm{mK}$ baseline noise level, $10 \mathrm{kHz}$ frequency resolution, $82^{\circ}$ zenith angle, and $0^{\circ}$ azimuthal angle (i.e. north-pointing) located at Kilpisjärvi $\left(69^{\circ} 03^{\prime} \mathrm{N}, 20^{\circ} 48^{\prime} \mathrm{E}\right)$, Finland, in clear-sky December conditions. Rows of the Jacobian matrix for selected altitude levels are plotted in (a). The grey scale in (b) indicates the values of the Jacobian matrix.

ground-based passive microwave measurements in the $\mathrm{Ku}$ band $11-14 \mathrm{GHz}$ region and OEM retrieval. At these frequencies tropospheric attenuation is small and mesospheric emission signals are transmitted to the ground with low loss. Comparable high atmospheric transmittances are calculated for various high-latitude $\mathrm{NH}$ and Antarctic sites in winter and summer, suggesting that different meteorology and location should have little impact on the proposed $\mathrm{O}_{3}$ and $\mathrm{OH}$ observations.

For a radiometer performing $6 \mathrm{~h}$ measurements of the $11.072 \mathrm{GHz} \mathrm{O}_{3}$ emission line with $10 \mathrm{kHz}$ frequency resolution and a rms baseline noise of $1 \mathrm{mK}, \mathrm{O}_{3}$ could be profiled over $8 \times 10^{-4}-0.22 \mathrm{hPa}(\sim 98-58 \mathrm{~km})$ with $11-18 \mathrm{~km}$ height resolution ( $\sim 12 \mathrm{~km}$ from DOFS analysis) and $\sim 1 \mathrm{ppmv}$ uncertainty. For the equivalent $\mathrm{OH} 13.441 \mathrm{GHz}$ measurement, demonstrated for vertical sensor polarisation, $\mathrm{OH}$ could be profiled over $3 \times 10^{-3}-0.29 \mathrm{hPa}(\sim 90-56 \mathrm{~km})$, also with 10 $17 \mathrm{~km}$ height resolution $(\sim 11 \mathrm{~km}$ from DOFS analysis) and $\sim 3$ ppbv uncertainty. Such observations would allow the diurnal variations in mesospheric $\mathrm{O}_{3}$ and $\mathrm{OH}$ to be characterised when abundances are relatively high, e.g. during night-time and polar winter. Measurement times of $24 \mathrm{~h}$ or longer would be necessary with less sensitive receivers or for measuring lower abundances. However, these measurements would still provide valuable data, in particular for the secondary ozone layer above $90 \mathrm{~km}$ as satellite measurements of this region become increasingly sparse. We have used simulations of atmospheric spectra from Kilpisjärvi, Finland, as a test case to assess the feasibility of such measurements but demonstrate that similar results would be achieved by instruments deployed at other high-latitude NH sites and in Antarctica.
LNB receivers operating at the Ku-band emission frequencies of $\mathrm{O}_{3}$ and $\mathrm{OH}$ are commercially available. LNBs covering the $\mathrm{O}_{3}$ frequency $(11.072 \mathrm{GHz})$ have a noise factor typically in the range $0.7-1.3 \mathrm{~dB}$, although suppliers specify values as low as $0.1 \mathrm{~dB}$. For coverage of the $\mathrm{OH}$ emission line frequency $(13.441 \mathrm{GHz})$ the stated LNB noise factor is $\sim 1.2 \mathrm{~dB}$. However, measurements reported by Tenneti and Rogers (2009) suggest that inexpensive satellite TV downconverters can achieve a noise factor as low as $\sim 0.23 \mathrm{~dB}$. If this high level of LNB performance is confirmed, a single receiver operating at room temperature would achieve $6 \mathrm{~h} \mathrm{O}_{3}$ spectrum measurements with the required rms baseline noise level of $1 \mathrm{mK}$. Otherwise, for the proposed $\mathrm{O}_{3}$ and $\mathrm{OH}$ observations, either simultaneous measurements by an array of multiple receivers or using single receivers cooled to $\sim 168 \mathrm{~K}$ for $\mathrm{O}_{3}$ and $\sim 46 \mathrm{~K}$ for $\mathrm{OH}$ would be needed. Monitoring of $\mathrm{O}_{3}$ in the same volume of the atmosphere using three LNB receivers mounted in front of a "Direct TV" offset parabolic dish has been reported (Rogers et al., 2012). With six spectrometers simultaneously measuring both polarisations from each of the three receivers, in the ideal case the improvement in signal-to-noise ratio compared to a single radiometer is $\sqrt{6}=\sim 2.4$, although non-optimum matching of the LNB beam profiles and antenna focus would impact the performance. Scaling up to 24 independent spectrometers for the $\mathrm{O}_{3}$ measurements would be relatively straightforward using 12 receivers each measuring both polarisations, mounted singly or with two or three LNBs bundled together at each antenna focus point. Atmospheric observations recorded by each spectrometer could then be combined to achieve a $\sqrt{24}=\sim 4.9$ improvement in signal-to-noise ratio. For $\mathrm{OH}$, the greater complexity and cost of constructing 80 independent spectrometers operating at $13.441 \mathrm{GHz}$ could 
make use of a single low-temperature receiver the better option. For low-temperature operation, liquid nitrogen-cooled cryostats readily attain $\sim 90 \mathrm{~K}$, meeting the requirements for $\mathrm{O}_{3}$ observations. However, this cooling method requires a supply of liquid nitrogen into either a continuous flow or reservoir design of cryostat. Alternatively, LNBs mounted on the cold-head of a Gifford-McMahon closed-cycle helium cryocooler (e.g. Radebaugh, 2009; de Waele, 2011) could be operated continuously at temperatures in the range $4-77 \mathrm{~K}$.

The next steps towards developing suitable instruments include selecting and testing commercially available LNB receiver and antenna components and verifying the optimum configuration for making the proposed mesospheric $\mathrm{O}_{3}$ and $\mathrm{OH}$ observations. If tests confirm that low-cost satellite TV components can reliably achieve the desired performance (e.g. LNBs with a noise factor of $0.23 \mathrm{~dB}$ or lower) then the increased complexity and cost of designing and building a system using numerous multiple receivers or cryogenic cooling would be avoided, for $\mathrm{O}_{3} 11.072 \mathrm{GHz}$ measurements at least. It should be noted that other natural and artificial sources may produce signals at frequencies that overlap the $\mathrm{O}_{3}$ and $\mathrm{OH}$ microwave emissions. Potential interference from such sources may be mitigated by observing at remote high-latitude locations and by carefully pointing the receiver antenna to minimise directional pickup of spurious signals in the instrument field of view. OH microwave line Zeeman splitting needs to be adequately modelled in the retrieval algorithm, and the spectroscopic parameters need to be verified and optimised. Furthermore, during geomagnetic storms, rapid, localised fluctuations in the Earth's magnetic field can occur, which may not be well reproduced by a priori data from models such as IGRF. Instead, a better approach may be to use magnetometer data provided by nearby geophysical observatories to constrain the $\mathrm{OH}$ retrievals, or to allow the retrieval to adjust the magnetic field from a priori values to give an optimum fit to the observed line shape.

Data availability. The model and simulation datasets used in this study are available from the UK Polar Data Centre (https://doi.org/10.5285/57858a9a-d814-412c-8e799a542cd055d4; Newnham et al., 2018b).

Author contributions. DAN performed the ozone and hydroxyl microwave spectrum and retrieval simulations, and co-ordinated the study. AS and PTV carried out atmospheric model calculations and provided model data inputs for the simulation study. MAC and MK provided technical data on the configuration and performance of existing $11.072 \mathrm{GHz}$ ozone spectrometers. All authors discussed the results and commented on the paper.

Competing interests. The authors declare that they have no conflict of interest.
Acknowledgements. This work has been supported in part by the UK's Natural Environment Research Council (NERC) Technologies Proof-of-Concept grant reference NE/P003478/1 "Satellite TV-based Ozone and $\mathrm{OH}$ Observations using Radiometric Measurements $\left(\mathrm{STO}_{3} \mathrm{RM}\right)$ ") awarded to David A. Newnham. The work of Pekka T. Verronen was supported by the Academy of Finland (project 276926 - SECTIC: Sun-Earth Connection Through Ion Chemistry). The authors thank the ARTS and Qpack development teams and Peter Kirsch at BAS for assistance configuring and running the code, Monika E. Andersson (FMI) for providing WACCM-D datasets, and Alan E. E. Rogers at the Massachusetts Institute of Technology (MIT) Haystack Observatory for helpful discussions. Aaron Hendry is acknowledged for providing computer code (GEO2CGM) to facilitate the conversion from spherical geographic coordinates to spherical corrected geomagnetic coordinates.

Edited by: Gabriele Stiller

Reviewed by: three anonymous referees

\section{References}

Andersson, M. E., Verronen, P. T., Rodger, C. J., Clilverd, M. A., and Seppälä, A.: Missing driver in the Sun-Earth connection from energetic electron precipitation impacts mesospheric ozone, Nat. Commun., 5, 5197, https://doi.org/10.1038/ncomms6197, 2014a.

Andersson, M. E., Verronen, P. T., Rodger, C. J., Clilverd, M. A., and Wang, S.: Longitudinal hotspots in the mesospheric $\mathrm{OH}$ variations due to energetic electron precipitation, Atmos. Chem. Phys., 14, 1095-1105, https://doi.org/10.5194/acp-141095-2014, 2014b.

Arsenovic, P., Rozanov, E., Stenke, A., Funke, B., Wissing, J. M., Mursula, K., Tummon, F., and Peter, T.: The influence of middle range energy electrons on atmospheric chemistry and regional climate, J. Atmos. Sol.-Terr. Phy., 149, 180-190, https://doi.org/10.1016/j.jastp.2016.04.008, 2016.

Baumgaertner, A. J. G., Seppälä, A., Jöckel, P., and Clilverd, M. A.: Geomagnetic activity related $\mathrm{NO}_{x}$ enhancements and polar surface air temperature variability in a chemistry climate model: modulation of the NAM index, Atmos. Chem. Phys., 11, 45214531, https://doi.org/10.5194/acp-11-4521-2011, 2011.

Brasseur, G. P. and Solomon, S.: Aeronomy of the Middle Atmosphere, 3rd Edn., Springer, Dordrecht, the Netherlands, 2005.

Brinksma, E. J., Meijer, Y. J., McDermid, I. S., Cageao, R. P., Bergwerff, J. B., Swart, D. P. J., Ubachs, W., Matthews, W. A., Hogervorst, W., and Hovenier, J. W.: First lidar observations of mesospheric hydroxyl, Geophys. Res. Lett., 25, 51-54, https://doi.org/10.1029/97GL53561, 1998a.

Brinksma, E. J., Meijer, Y. J., McDermid, I. S., Cageao, R. P., Bergwerff, J. B., Swart, D. P. J., Ubachs, W., Matthews, W. A., Hogervorst, W., and Hovenier, J. W.: Correction to "First lidar observations of mesospheric hydroxyl”, Geophys. Res. Lett., 25, 521, https://doi.org/10.1029/98GL00119, 1998b.

Buehler, S. A., Eriksson, P., Kuhn, T., von Engeln, A., and Verdes, C.: ARTS, the atmospheric radiative transfer simulator, J. Quant. Spectrosc. Ra., 91, 65-93, https://doi.org/10.1016/j.jqsrt.2004.05.051, 2005. 
Buehler, S. A., Mendrok, J., Eriksson, P., Perrin, A., Larsson, R., and Lemke, O.: ARTS, the Atmospheric Radiative Transfer Simulator - version 2.2, the planetary toolbox edition, Geosci. Model Dev., 11, 1537-1556, https://doi.org/10.5194/gmd-111537-2018, 2018.

Christensen, O. M. and Eriksson, P.: Time series inversion of spectra from ground-based radiometers, Atmos. Meas. Tech., 6, 15971609, https://doi.org/10.5194/amt-6-1597-2013, 2013.

Clancy, R. T., Sandor, B. J., Rusch, D. W., and Muhleman, D. O.: Microwave observations and modeling of $\mathrm{O}_{3}, \mathrm{H}_{2} \mathrm{O}$, and $\mathrm{HO}_{2}$ in the mesosphere, J. Geophys. Res., 99, 5465-5473, https://doi.org/10.1029/93JD03471, 1994.

Clough, S., Shephard, M., Mlawer, E., Delamere, J., Iacono, M., Cady-Pereira, K., Boukabara, S., and Brown, P.: Atmospheric radiative transfer modeling: a summary of the AER codes, J. Quant. Spectrosc. Ra., 91, 233-244, 2005.

Cresswell-Moorcock, K., Rodger, C. J., Kero, A., Collier, A. B., Clilverd, M. A., Häggström, I., and Pitkänen, T.: A reexamination of latitudinal limits of substorm-produced energetic electron precipitation, J. Geophys. Res.-Space, 118, 6694-6705, https://doi.org/10.1002/jgra.50598, 2013.

Daae, M., Straub, C., Espy, P. J., and Newnham, D. A.: Atmospheric ozone above Troll station, Antarctica observed by a ground based microwave radiometer, Earth Syst. Sci. Data, 6, 105-115, https://doi.org/10.5194/essd-6-105-2014, 2014.

de Waele, A. T. A. M.: Basic operation of cryocoolers and related thermal machines, J. Low Temp. Phys., 164, 179, https://doi.org/10.1007/s10909-011-0373-x, 2011.

Englert, C. R., Stevens, M. H., Siskind, D. E., Harlander, J. M., and Roesler, F. L.: Spatial Heterodyne Imager for Mesospheric Radicals on STPSat-1, J. Geophys. Res., 115, D20306, https://doi.org/10.1029/2010JD014398, 2010.

Eriksson, P., Jiménez, C., and Buehler, S. A.: Qpack, a general tool for instrument simulation and retrieval work, J. Quant. Spectrosc. Ra., 91, 47-64, https://doi.org/10.1016/j.jqsrt.2004.05.050, 2005.

Eriksson, P., Buehler, S. A., Davis, C. P., Emde, C., and Lemke, O.: ARTS, the atmospheric radiative transfer simulator, version 2, J. Quant. Spectrosc. Ra., 112, 1551-1558, https://doi.org/10.1016/j.jqsrt.2011.03.001, 2011.

Finlay, C. C., Maus, S., Beggan, C. D., Bondar, T. N., Chambodut, A., Chernova, T. A., Chulliat, A., Golovkov, V. P., Hamilton, B., Hamoudi, M., Holme, R., Hulot, G., Kuang, W., Langlais, B., Lesur, V., Lowes, F. J., Lühr, H., Macmillan, S., Mandea, M., McLean, S., Manoj, C., Menvielle, M., Michaelis, I., Olsen, N., Rauberg, J., Rother, M., Sabaka, T. J., Tangborn, A., TøffnerClausen, L., Thébault, E., Thomson, A. W. P., Wardinski, I., Wei, Z., and Zvereva, T. I.: International geomagnetic reference field: The eleventh generation, Geophys. J. Int., 183, 1216-1230, https://doi.org/10.1111/j.1365-246X.2010.04804.x, 2010.

Froidevaux, L., Jiang, Y. B., Lambert, A., Livesey, N. J., Read, W. G., Waters, J. W., Browell, E. V., Hair, J. W., Avery, M. A., McGee, T. J., Twigg, L. W., Sumnicht, G. K., Jucks, K. W., Margitan, J. J., Sen, B., Stachnik, R. A., Toon, G. C., Bernath, P. F., Boone, C. D., Walker, K. A., Filipiak, M. J., Harwood R. S., Fuller, R. A., Manney, G. L., Schwartz, M. J., Daffer, W. H., Drouin, B. J., Cofield, R. E., Cuddy, D. T., Jarnot, R. F., Knosp, B. W., Perun, V. S., Snyder, W. V., Stek, P. C., Thurstans, R. P., and Wagner, P. A.: Validation of Aura Microwave Limb
Sounder stratospheric ozone measurements, J. Geophys. Res., 113, D15S20, https://doi.org/10.1029/2007JD008771, 2008.

Gordon, I. E., Rothman, L. S., Hill, C., Kochanov, R. V., Tan, Y., Bernath, P. F., Birk, M., Boudon, V., Campargue, A., Chance, K. V., Drouin, B. J., Flaud, J.-M., Gamache, R. R., Hodges, J. T., Jacquemart, D., Perevalov, V. I., Perrin, A., Shine, K. P., Smith, M.-A. H., Tennyson, J., Toon, G. C., Tran, H., Tyuterev, V. G., Barbe, A., Császár, A. G., Devi, V. M., Furtenbacher, T., Harrison, J. J., Hartmann, J.-M., Jolly, A., Johnson, T. J., Karman, T., Kleiner, I., Kyuberis, A. A., Loos, J., Lyulin, O. M., Massie, S. T., Mikhailenko, S. N., Moazzen-Ahmadi, N., Müller, H. S. P., Naumenko, O. V., Nikitin, A. V., Polyansky, O. L., Rey, M., Rotger, M., Sharpe, S. W., Sung, K., Starikova, E., Tashkun, S. A., Vander Auwera, J., Wagner, G., Wilzewski, J., Wcislo, P., Yu, S., and Zak, E. J.: The HITRAN2016 molecular spectroscopic database, J. Quant. Spectrosc. Ra., 203, 3-69, https://doi.org/10.1016/j.jqsrt.2017.06.038, 2017.

Hartogh, P., Jarchow, C., Sonnemann G. R., and Grygalashvyly, M.: On the spatiotemporal behavior of ozone within the mesosphere/mesopause region during nearly polar night conditions, J. Geophys. Res., 109, D18303, https://doi.org/10.1029/2004JD004576, 2004.

Jackman, C. H. and McPeters, R. D.: The effect of solar proton events on ozone and other constituents, Solar variability and its effects on climate, Geophysical Monograph Series, Vol. 141, 305-319, American Geophysical Union, Washington, DC, https://doi.org/10.1029/141GM21, 2004.

Kraus, J. D.: Radio astronomy, Powell, Ohio, Cygnus-Quasar, 2nd Edn., ISBN 10-1882484002, ISBN 13-9781882484003, 1986.

Kuntz, M.: A new implementation of the Humlicek algorithm for the calculation of the Voigt profile function, J. Quant. Spectrosc. Ra., 57, 819-824, 1997.

Larsson, R., Buehler, S. A., Eriksson P., and Mendrok, J.: A treatment of the Zeeman effect using Stokes formalism and its implementation in the Atmospheric Radiative Transfer Simulator (ARTS), J. Quant. Spectrosc. Ra., 133, 445-453, https://doi.org/10.1016/j.jqsrt.2013.09.006, 2014.

Marsh, D. R., Mills, M. J., Kinnison, D. E., and Lamarque, J.-F.: Climate change from 1850 to 2005 simulated in CESM1 (WACCM), J. Climate, 26, 7372-7391, https://doi.org/10.1175/JCLI-D-12-00558.1, 2013.

Melsheimer, C., Verdes, C., Buehler, S. A., Emde, C., Eriksson, P., Feist, D. G., Ichizawa, S., John, V. O., Kasai, Y., Kopp, G., Koulev, N., Kuhn, T., Lemke, O., Ochiai, S., Schreier, F., Sreerekha, T. R., Suzuki, M., Takahashi, C., Tsujimaru, S., and Urban, J.: Intercomparison of general purpose clear sky atmospheric radiative transfer models for the millimeter/submillimeter spectral range, Radio Sci., 40, RS1007, https://doi.org/10.1029/2004RS003110, 2005.

Minschwaner, K., Manney, G. L., Wang, S. H., and Harwood, R. S.: Hydroxyl in the stratosphere and mesosphere - Part 1: Diurnal variability, Atmos. Chem. Phys., 11, 955-962, https://doi.org/10.5194/acp-11-955-2011, 2011.

Mironova, I. A., Aplin, K. L., Arnold, F., Bazilevskaya, G. A., Harrison, R. G., Krivolutsky, A. A., Nicoll, K. A., Rozanov, E. V., Turunen, E., and Usoskin, I. G.: Energetic particle influence on the Earth's atmosphere, Space Sci. Rev., 194, 1-96, https://doi.org/10.1007/s11214-015-0185-4, 2015. 
Mlawer, E. J., Payne, V. H., Moncet, J.-L., Delamere, J. S., Alvarado, M. J., and Tobin, D. C.: Development and recent evaluation of the MT-CKD model of continuum absorption, Philos. T. R. Soc. A, 370, 2520-2556, 2012.

Newnham, D. A., Clilverd, M. A., Rodger, C. J., Hendrickx, K., Megner, L., Kavanagh, A. J., Seppälä, A., Verronen, P. T., Andersson, M. E., Marsh, D. R., Kovács, T., Feng, W., and Plane, J. M. C.: Observations and modeling of increased nitric oxide in the Antarctic polar middle atmosphere associated with geomagnetic storm-driven energetic electron precipitation, J. Geophys. Res.-Space, 123, https://doi.org/10.1029/2018JA025507, 2018a.

Newnham, D., Verronen, P., and Seppälä, A.: Model data for simulating atmospheric microwave spectra at $11.072 \mathrm{GHz}$ and $13.441 \mathrm{GHz}$ and performing retrievals of ozone $\left(\mathrm{O}_{3}\right)$ and hydroxyl $(\mathrm{OH})$ vertical profiles, Polar Data Centre, Natural Environment Research Council, UK, https://doi.org/10.5285/57858a9a-d814-412c-8e799a542cd055d4, 2018b.

Pickett, H. M., Drouin, B. J., Canty, T., Salawitch, R. J., Fuller, R. A., Perun, V. S., Livesey, N. J., Waters, J. W., Stachnik, R. A., Sander, S. P., Traub, W. A., Jucks, K. W., and Minschwaner, K.: Validation of Aura Microwave Limb Sounder $\mathrm{OH}$ and $\mathrm{HO}_{2}$ measurements, J. Geophys. Res., 113, D16S30, https://doi.org/10.1029/2007JD008775, 2008.

Radebaugh, R.: Cryocoolers: the state of the art and recent developments, J. Phys.-Condens. Mat., 21, 164219, https://doi.org/10.1088/0953-8984/21/16/164219, 2009.

Radford, H. E.: Microwave Zeeman effect of free hydroxyl radicals, Phys. Rev., 122, 114, https://doi.org/10.1103/PhysRev.122.114, 1961

Rodger, C. J., Cresswell-Moorcock, K., and Clilverd, M. A.: Nature's Grand Experiment: Linkage between magnetospheric convection and the radiation belts, J. Geophys. Res.-Space, 121, 171-189, https://doi.org/10.1002/2015JA021537, 2016.

Rodgers, C. D.: Inverse methods for atmospheric sounding: Theory and Practice, Vol. 2 of Series on Atmospheric, Ocean and Planetary Physics, World Scientific, https://doi.org/10.1142/3171, 2000.

Rogers, A. E. E., Lekberg, M., and Pratap, P.: Seasonal and diurnal variations of ozone near the mesopause from observations of the 11.072-GHz line, J. Atmos. Ocean. Tech., 26, 2192-2199, https://doi.org/10.1175/2009JTECHA1291.1, 2009.

Rogers, A. E. E., Erickson, P., Fish, V. L., Kittredge, J., Danford, S., Marr, J. M., Arndt, M. B., Sarabia, J., Costa, D., and May, S. K.: Repeatability of the seasonal variations of ozone near the mesopause from observations of the 11.072-GHz line, J. Atmos. Ocean. Tech., 29, 1492-1504, https://doi.org/10.1175/JTECHD-11-00193.1, 2012.

Ryan, N. J., Walker, K. A., Raffalski, U., Kivi, R., Gross, J., and Manney, G. L.: Ozone profiles above Kiruna from two ground-based radiometers, Atmos. Meas. Tech., 9, 4503-4519, https://doi.org/10.5194/amt-9-4503-2016, 2016.

Sastry, K. V. L. N. and Vanderlinde, J.: Low-field Zeeman effect of $\mathrm{OH}$ in the ${ }^{2} \Pi_{3 / 2}, J=7 / 2,9 / 2,11 / 2,13 / 2$, and $15 / 2$ states, J. Mol. Spectrosc., 83, 332-338, https://doi.org/10.1016/00222852(80)90057-0, 1980

Semeniuk, K., Fomichev, V. I., McConnell, J. C., Fu, C., Melo, S. M. L., and Usoskin, I. G.: Middle atmosphere response to the solar cycle in irradiance and ionizing particle precipitation, At- mos. Chem. Phys., 11, 5045-5077, https://doi.org/10.5194/acp11-5045-2011, 2011.

Seppälä, A., Randall, C. E., Clilverd, M. A., Rozanov, E., and Rodger, C. J.: Geomagnetic activity and polar surface air temperature variability, J. Geophys. Res.-Space, 114, A10312, https://doi.org/10.1029/2008JA014029, 2009.

Seppälä, A., Lu, H., Clilverd, M. A., and Rodger, C. J.: Geomagnetic activity signatures in wintertime stratosphere wind, temperature, and wave response, J. Geophys. Res.-Atmos., 118, 2169 2183, https://doi.org/10.1002/jgrd.50236, 2013.

Seppälä, A., Clilverd, M. A., Beharrell, M. J., Rodger, C. J., Verronen, P. T., Andersson, M. E., and Newnham, D. A.: Substorm-induced energetic electron precipitation: Impact on atmospheric chemistry, Geophys. Res. Lett., 42, 8172-8176, https://doi.org/10.1002/2015GL065523, 2015.

Sinnhuber, M., Nieder, H., and Wieters, N.: Energetic particle precipitation and the chemistry of the mesosphere/lower thermosphere, Surv. Geophys., 33, 1281-1334, https://doi.org/10.1007/s10712-012-9201-3, 2012.

Siskind, D. E., Stevens, M. H., Englert, C. R., and Mlynczak, M. G.: Comparison of a photochemical model with observations of mesospheric hydroxyl and ozone, J. Geophys. Res., 118, 195207, https://doi.org/10.1029/2012JD017971, 2013.

Smith, A. K., Harvey, V. L., Mlynczak, M. G., Funke, B., GarcíaComas, M., Hervig, M., Kaufmann, M., Kyrölä, E., LópezPuertas, M., McDade, I., Randall, C. E., Russell III, J. M., Sheese, P. E., Shiotani, M., Skinner, W. R., Suzuki, M., and Walker, K. A.: Satellite observations of ozone in the upper mesosphere, J. Geophys. Res.-Atmos., 118, 5803-5821, https://doi.org/10.1002/jgrd.50445, 2013.

Smith, S. M., Baumgardner, J., Mertens, C. J., Russell, J. M., Mlynczak, M. G., and Mendillo, M.: Mesospheric OH temperatures: Simultaneous ground-based and SABER OH measurements over Millstone Hill, Adv. Space Res., 45, 239-246, https://doi.org/10.1016/j.asr.2009.09.022, 2010.

Summers, M. E., Conway, R. R., Siskind, D. E., Stevens, M. H., Offermann, D., Riese, M., Preusse, P., Strobel, D. F., and Russell III, J. M.: Implications of satellite $\mathrm{OH}$ observations for middle atmospheric $\mathrm{H}_{2} \mathrm{O}$ and ozone, Science, 277, 1967-1969, 1997.

Tenneti, S. N. and Rogers, A. E. E.: Development of an optimized antenna and other enhancements of a spectrometer for the study of ozone in the mesosphere, VSRT and MOSAIC Memo 063, available at: https://www.haystack.mit.edu/edu/undergrad/ VSRT/VSRT_Memos/063.pdf (last access: 21 February 2019), 2009.

Thébault, E., Finlay, C. C., Beggan, C. D., Alken, P., Aubert, J., Barrois, O., Bertrand, F., Bondar, T., Boness, A., Brocco, L., Canet, E., Chambodut, A., Chulliat, A., Coïsson, P., Civet, F., Du, A., Fournier, A., Fratter, I., Gillet, N., Hamilton, B., Hamoudi, M., Hulot, G., Jager, T., Korte, M., Kuang, W., Lalanne, X., Langlais, B., Léger, J.-M., Lesur, V., Lowes, F. J., Macmillan, S., Mandea, M., Manoj, C., Maus, S., Olsen, N., Petrov, V., Ridley, V., Rother, M., Sabaka, T. J., Saturnino, D., Schachtschneider, R., Sirol, O., Tangborn, A., Thomson, A., Tøffner-Clausen, L., Vigneron, P., Wardinski, I., and Zvereva, T.: International Geomagnetic Reference Field: the 12th generation, Earth Planets Space, 67, 79, https://doi.org/10.1186/s40623-015-0228-9, 2015. 
Turunen, E., Verronen, P. T., Seppälä, A., Rodger, C. J., Clilverd, M. A., Tamminen, J., Enell, C.-F., and Ulich, T.: Impact of different energies of precipitating particles on $\mathrm{NO}_{x}$ generation in the middle and upper atmosphere during geomagnetic storms, J. Atmos. Sol.-Terr. Phy., 71, 1176-1189, https://doi.org/10.1016/j.jastp.2008.07.005, 2009.

Van Vleck, J. and Huber, D.: Absorption, emission, and linebreadths: A semi-historical perspective, Rev. Mod. Phys., 49, 939, https://doi.org/10.1103/RevModPhys.49.939, 1977.

Verronen, P. T. and Lehmann, R.: Analysis and parameterisation of ionic reactions affecting middle atmospheric $\mathrm{HO}_{x}$ and $\mathrm{NO}_{y}$ during solar proton events, Ann. Geophys., 31, 909-956, https://doi.org/10.5194/angeo-31-909-2013, 2013.

Verronen, P. T. and Lehmann, R.: Enhancement of odd nitrogen modifies mesospheric ozone chemistry during polar winter, Geophys. Res. Lett., 42, 10445-10452, https://doi.org/10.1002/2015GL066703, 2015.

Verronen, P. T., Seppälä, A., Clilverd, M. A., Rodger, C. J., Kyrölä, E., Enell, C.-F., Ulich, T., and Turunen, E.: Diurnal variation of ozone depletion during the October-November 2003 solar proton events, J. Geophys. Res., 110, A09S32, https://doi.org/10.1029/2004JA010932, 2005.

Verronen, P. T., Rodger, C. J., Clilverd, M. A., and Wang, S.: First evidence of mesospheric hydroxyl response to electron precipitation from the radiation belts, J. Geophys. Res., 116, D07307, https://doi.org/10.1029/2010JD014965, 2011.
Verronen, P. T., Andersson, M. E., Marsh, D. R., Kovács, T., and Plane, J. M. C.: WACCM-D - Whole Atmosphere Community Climate Model with D-region ion chemistry, J. Adv. Model. Earth Sy., 8, 954-975, https://doi.org/10.1002/2015MS000592, 2016.

von Zahn, U., Fricke, K. H., Gerndt, R., and Blix, T.: Mesospheric temperatures and the $\mathrm{OH}$ layer height as derived from groundbased lidar and $\mathrm{OH}^{*}$ spectrometry, J. Atmos. Terr. Phys., 49, 863-869, https://doi.org/10.1016/0021-9169(87)90025-0, 1987.

Yee, J.-H., Crowley, G., Roble, R. G., Skinner, W. R., Burrage, M. D., and Hays, P. B.: Global simulations and observations of $\mathrm{O}\left({ }^{1} \mathrm{~S}\right), \mathrm{O}_{2}\left({ }^{1} \Sigma\right)$ and $\mathrm{OH}$ mesospheric nightglow emissions, J. Geophys. Res., 102, 19949-19968, https://doi.org/10.1029/96JA01833, 1997.

Zawedde, A. E., NesseTyssøy, H., Stadsnes, J., and Sandanger, M. I.: The impact of energetic particle precipitation on mesospheric $\mathrm{OH}$ - Variability of the sources and the background atmosphere, J. Geophys. Res.-Space, 123, 5764-5789, https://doi.org/10.1029/2017JA025038, 2018.

Zhang, S. P. and Shepherd, G. S.: The influence of the diurnal tide on the $\mathrm{O}\left({ }^{1} \mathrm{~S}\right)$ and $\mathrm{OH}$ emission rates observed by WINDII on UARS, Geophys. Res. Lett., 26, 529-532, https://doi.org/10.1029/1999GL900033, 1999. 